\title{
UNIVERSITY FUNDRAISING THROUGH SPECIAL EVENTS: AN APPLICATION OF THE THEORY OF PLANNED BEHAVIOR
}

\author{
A Thesis \\ presented to \\ the Faculty of California Polytechnic State University, \\ San Luis Obispo \\ In Partial Fulfillment \\ of the Requirements for the Degree \\ Master of Science in Agriculture, with Specialization in \\ Recreation, Parks, \& Tourism Management
}

by

Megan Elizabeth Hobbs

September 2016 
(C) 2016

Megan Elizabeth Hobbs

ALL RIGHTS RESERVED 
TITLE: University Fundraising Through Special Events:

An Application of the Theory of Planned Behavior

AUTHOR: $\quad$ Megan Elizabeth Hobbs

DATE SUBMITTED: September 2016

COMMITTEE CHAIR: William Hendricks, Ph.D.

Professor of Recreation, Parks, and Tourism

Administration

COMMITTEE MEMBER: Jerusha Greenwood, Ph.D.

Associate Professor of Recreation, Parks, and Tourism Administration

COMMITTEE MEMBER: Kevin Lin, Ph.D.

Assistant Professor of Recreation, Parks, and Tourism Administration 


\section{ABSTRACT}

University Fundraising Through Special Events: An Application of the Theory of Planned Behavior

Megan Elizabeth Hobbs

The purpose of this study was to apply the Revised Theory of Planned Behavior and EVENTQUAL models to explore (1) event qualities that significantly impact guests' satisfaction with a university event that they attend, (2) significant factors influencing university loyalty as a result of an event, and (3) willingness to make a charitable donation to a university as a result of attending an event. An online survey was sent to attendees of an annual Cal Poly auction event between 2002 and 2016 that directly benefits Cal Poly students. The data were used to test a series of hypotheses to determine the fit of a proposed theoretical model.

Although the study was limited by a small sample size of 74 subjects, it resulted in the creation of a revised event fundraising model. Student involvement proved to be the only quality significantly predicting a guest's overall satisfaction with the event, explaining $12 \%$ of the variance. The combination of overall event satisfaction with a subset of the revised theory of planned behavior variables (attitude, descriptive norm, and moral norm) explained 51\% of the variance in predicting university loyalty. Finally, intention to donate was best predicted as a combination of prescriptive norm, attitude, and university loyalty, accounting for $57 \%$ of the variance.

Overall, the revised model is applicable in aspects of university event planning including event branding, marketing, and the involvement of students at the event. Of 
serious note is the statistically significant attitude variable. If an event planner can utilize a university event to shift the guests' attitudes towards the event and university, this can greatly enhance not only intention to donate at one particular event, but the loyalty these people feel to the university or program. 


\section{ACKNOWLEDGMENTS}

The author would like to thank Dr. William Hendricks, Dr. Kevin Lin, and Dr. Jerusha Greenwood for their guidance and encouragement. In addition, the author would like to thank the rest of the RPTA faculty and Kathy Daniels for their support throughout the graduate thesis process. Also, Dr. Karen McGaughey for statistical analysis assistance. Finally, this culminating thesis would not exist without the never-ending love and support from Mom, Dad, and Carolynn, and Jenny, Eileen and my Donor Relations family at Cal Poly. 


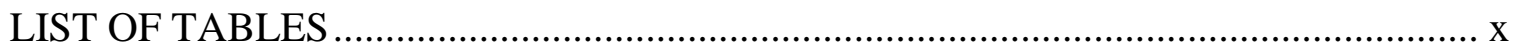

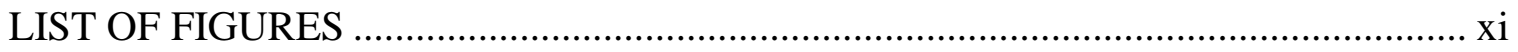

\section{CHAPTER}

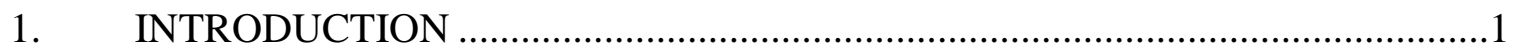

Background ..........................................................................................

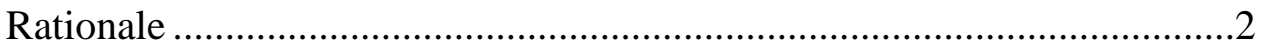

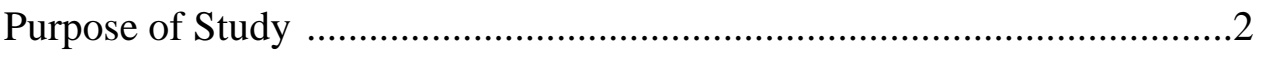

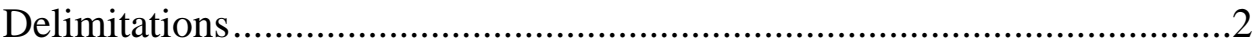

Definition of Key Terms ...........................................................................

2. LITERATURE REVIEW ………..........................................................

The Theory of Planned Behavior .....................................................................

Applied Theory: Intention to Attend Event ..................................................6

Motivations to Engage through Event Attendance .........................................7

Fostering Satisfaction to Encourage Event Loyalty......................................9

Evaluating Events .................................................................................10

Intention to Donate: A Revised TPB Model.................................................12

Charitable Giving in a University Setting: Further Research ......................13

University Events and Donation Behavior: A Missing Link .......................15

A New Model for University Fundraising through Strategic Events ........16

Hypothesis Statements ..............................................................................19 


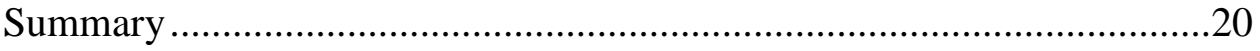

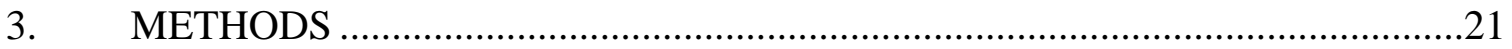

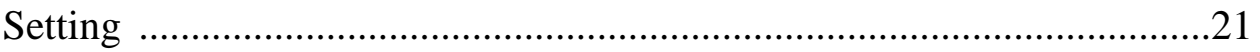

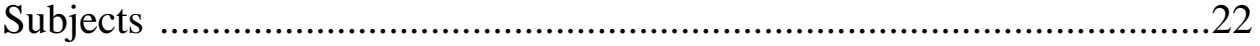

Instrument Design ......................................................................22

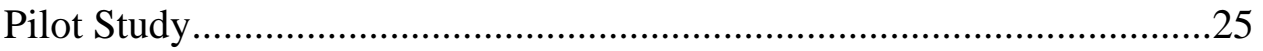

Data Collection Procedures ..................................................................225

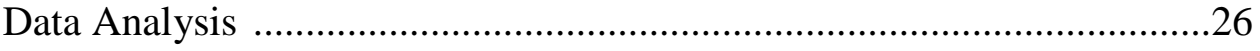

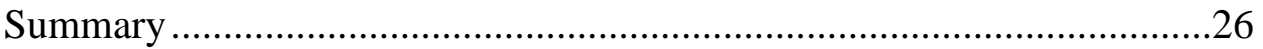

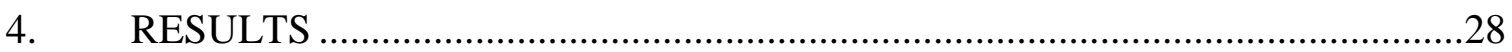

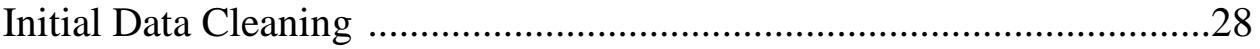

Respondent Demographics ........................................................29

Proposed Model Analyses ...............................................................30

Exploratory Factor Analyses: Consolidating Variables ..........................31

Simple Linear, Multiple, and Hierarchical Regression Analyses ..............36

Predicting Overall Satisfaction ........................................................38

Predicting Loyalty ...........................................................................38

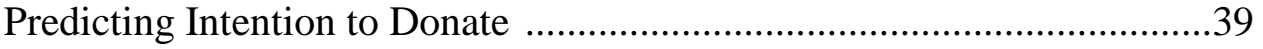

Hierarchical Multiple Regression ....................................................40

The Proposed Model .........................................................................42

Predicting Charitable Giving at a University Event: A Revised Model ...44

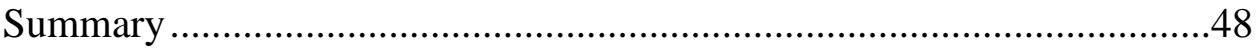




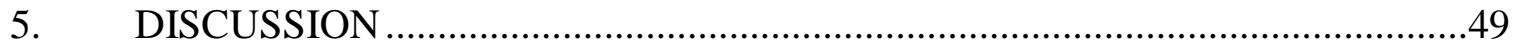

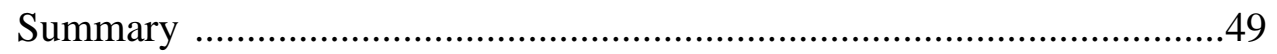

Discussion and Practical Implications .......................................................51

Study Limitations ................................................................................53

Future Research .................................................................................

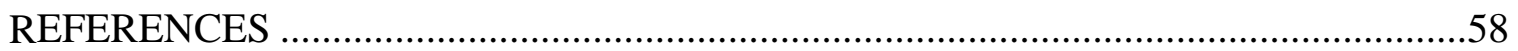

\section{APPENDICES}

A. Auction event attendee survey .............................................................62

B. Email to RPTA Auction Event Attendees ............................................72

C. Informed Consent Letter ......................................................................74 


\section{LIST OF TABLES}

Table Page

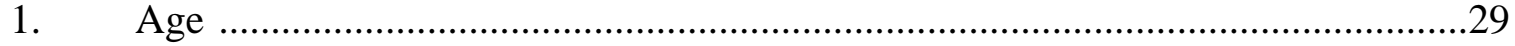

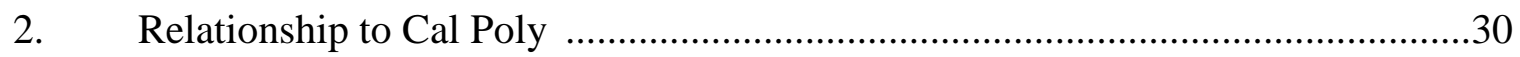

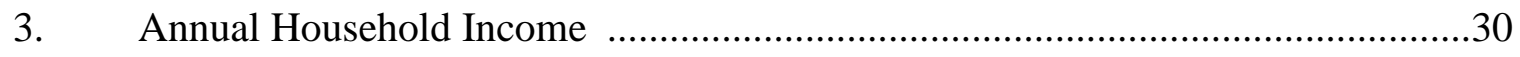

4. $\quad$ Factor Analysis of Variables Examined in H1 Hypotheses ...............................35

5. Descriptive Statistics and Intercorrelations for all Proposed Model Variables ......37

6. Coefficients in Predicting Overall Satisfaction .............................................38

7. Coefficients in Predicting University Loyalty ..............................................39

8. Coefficients in Predicting Intention to Donate through Loyalty .........................39

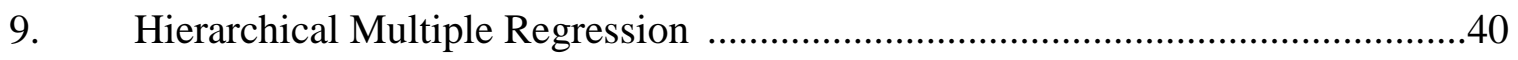

10. Coefficients in Predicting University/Program Loyalty, Full Model ...................45 


\section{LIST OF FIGURES}

Figure

Page

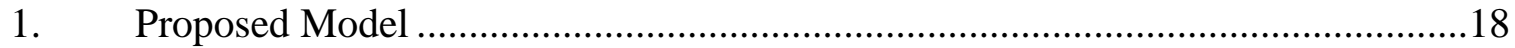

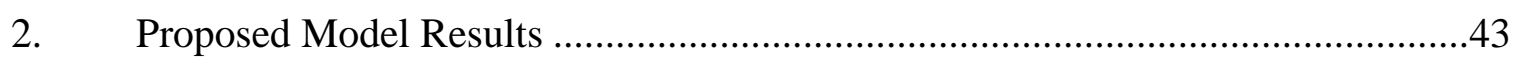

3. $\quad$ Revised Event Fundraising Model.......................................47 


\section{CHAPTER 1}

\section{INTRODUCTION}

With the ever-decreasing state support in funding for public universities, the need for private support has never been greater. Special events provide a unique platform to strengthen the relationship between a university and its potential donors. Understanding the reasons that people attend events, how to optimize satisfaction while encouraging guest loyalty, and how to transform that guest loyalty into motivation to make a charitable gift to a university has not been explored in previous research. Background

The theory of planned behavior (TPB), developed in health research to understand motivation, has been used extensively across many disciplines, including event attendance (Ajzen, 1991; Conner \& Armitage, 1998; Montano, Kasprzyk, Glanz, Rimer, \& Viswanath, 2008). There has also been extensive research that supports various measurements of service quality, some of which relates to events. However, the events studied with TPB have been either sporting events or festivals that have different purposes than university fundraising events. Furthermore, satisfaction and event loyalty have been used to measurement event success, but not in a university setting. Finally, the literature suggests a connection between the theory of planned behavior and charitable giving (Smith \& McSweeney, 2007; van der Linden, 2011). However, research also suggests that in order to be able to predict giving behavior, one must adopt a revised theory of planned behavior model to include two additional variables: past behavior and moral norms (Smith \& McSweeney). In addition, there is research that suggests 
additional motives beyond those included in TPB (van der Linden). These include motivations of university giving but not through the application of the theory of planned behavior or through the use of special events as a catalyst for such donations.

\section{Rationale}

The literature on the theory of planned behavior specific to events, combined with research on how event satisfaction enhances event loyalty, can help administrators and faculty understand how motivation relates to charitable giving in a university setting. University advancement teams rely on events to bring the university and potential donors together. However, research on what motivates someone to attend an event, stay loyal to the event, and how that translates into motivations to make a charitable contribution to the university, is lacking.

Purpose of Study

The purpose of this study was to apply the Revised Theory of Planned Behavior and EVENTQUAL models to explore (1) event qualities that significantly impact guests’ satisfaction with a university event that they attend, (2) significant factors influencing university loyalty as a result of an event, and (3) willingness to make a charitable donation to a university as a result of attending an event.

\section{Delimitations}

1. Research was delimited to one California Polytechnic State University event: The Recreation, Parks, and Tourism Administration Department's annual auction and dinner fundraiser.

2. Data collection was delimited to email addresses collected by the Cal Poly RPTA department over the 15 year history of the event. 
3. Data were delimited to individuals that supplied an event planner with an accurate email address, and that still utilized that email address in February 2016, or individuals that actively follow Cal Poly RPTA’s Facebook Page who were able to see the posted survey link.

\section{Definition of Key Terms}

The following terms are defined as used in the study:

Charitable donation: For this study, this is the financial contribution beyond the cost of a guest's ticket. This is the portion that is considered tax-deductible as the Cal Poly Corporation is a non-profit 501(c)(3). This amount can also be in the form of donation of goods and services.

Descriptive social norms: Descriptive social norms "merely describe the behavior of significant others" (van der Linden, 2011, p. 359).

Loyalty: Yoon, Lee, \& Lee (2009) describe loyalty in the context of events as behavioral intentions. The Merriam-Webster dictionary definition recognizes loyalty as "a feeling of strong support of someone or something."

Moral norms: Moral norms are broadly defined as an individual's internalized code of conduct (Parker, Manstead, \& Stradling, 1995). Moral norms "refer to the idea that some behaviors are just inherently right or wrong regardless of their personal or social consequences" (van der Linden, p. 358).

Motivation: Motivation drives and enthuses people, giving them the commitment to achieve goals (Bowdin, Allen, O’Toole, Harris, \& McDonnell, 2006). Darlington (2009) describes motivation as getting someone to do something because they want to do it. 
Perceived behavioral control: Perceived behavioral control refers to perception of control over a given behavior (van der Linden).

Prescriptive social norms : "Prescriptive social norms refer to the social expectation of how an individual ought to behave” (van der Linden, p. 358).

Satisfaction: Yoon et al. (2009) describe satisfaction as "an emotional state affected by both quality attributes and extraneous factors (e.g., mood and climate) experienced by visitors” (p. 336). Satisfaction is the result of needs being fulfilled (Crompton \& McKay, 1997).

Social norms: Social norms are the combination of descriptive and prescriptive social norms (van der Linden).

Subjective norms: Subjective norms are "whether important referent individuals approve or disapprove of performing the behavior, weighted by his or her motivation to comply with those referents. A person who believes that certain referents think she should perform a behavior and is motivated to meet expectations of those referents will hold a positive subjective norm” (Montano, et al., 2008, p. 71). 


\section{CHAPTER 2}

\section{LITERATURE REVIEW}

The literature on the theory of planned behavior related to events, combined with research on how event satisfaction can enhance event loyalty (EVENTQUAL), can help understand motivations behind charitable giving to a university. Research on what motivates someone to attend an event, event loyalty, and how that translates into motivations to make a charitable contribution to the university, is lacking. Therefore, this literature review will analyze the literature on both the Theory of Planned Behavior and EVENTQUAL to propose an adapted model in an effort to bridge this gap in research for university fundraising through effective events.

\section{The Theory of Planned Behavior}

The theory of planned behavior (Ajzen, 1991) suggests that three dimensions make up intent to behave in a certain way: attitude toward the behavior, subjective norms, and perceived behavioral control. Previous research indicates that intention is the strongest predictor of actual behavior (Ajzen, 1991). This theory has been applied across multiple disciplines including consumer buying habits, business, psychology, sports, and leisure studies (Ajzen \& Driver, 2009; Ajzen \& Madden, 1986; Conner \& Abraham, 2001; Cunningham \& Kwon, 2003; Hansen, Jensen, Solgaard, 2004; Pavlou \& Fygenson, 2006). Behavioral attitude is made up of two factors: affective (e.g. will this behavior be enjoyable?) and instrumental (e.g. will this behavior be beneficial or harmful?). Subjective norms are injunctive (e.g. do others encourage behavior?) and descriptive (e.g are friends/family participating in behavior as well?) norms. Finally, perceived 
behavioral control has two components: if one is capable of or confident in a behavior and if one can overcome any barriers or challenges that arise from a behavior.

This theory can be applied to university fundraising by looking at two related pieces: intent to attend an event and intent to make a charitable contribution to the university hosting the event. An understanding of how people are motivated to attend an event can be used in event marketing, program, design, pricing, and evaluation. To take the role of university events one step further, this theory can be applied to university giving through an event once guests have the intention to attend and subsequently take action by attending an event.

Applied Theory: Intention to Attend Event

The theory of planned behavior can be applied directly to understand motivations to attend an event. For example, intentions to attend a sport event have been studied through the application of the theory of planned behavior (Cunningham \& Kwon, 2003). Cunningham and Kwon found that attitude, subjective norms, and perceived behavioral control all had a significantly positive relationship with intention to attend a sporting event. However, they did not find that attitudes and subjective norms are more positively related to intent than behavioral control. This suggests some interesting implications for event planners. In the context of event attendance, asking if the participants believe the event would be enjoyable would measure affective attitude and asking if attending the event would benefit them would measure instrumental attitude. The authors examined the subjective norms component, the combination of others encouraging behavior and friends participating in such behavior (attending events) and found that subjective norms did not hold a more positive relationship with behavioral intent than perceived behavioral 
control. Finally, this study's results suggested an additional variable, previous behavior, may be important to giving. Cunningham and Kwon found that previous behavior, combined with the three TPB dimensions, have a positive association with intent to attend a sporting event. As past behavior appears to be a strong indicator of intent to attend future events, event professionals can use this information to determine the best way to foster repeat attendance through evaluation of event satisfaction. This in turn will likely create event loyalty.

\section{Motivations to Engage through Event Attendance}

Getz and Cheyne (2002) popularized a theoretical framework with three dimensions to evaluate special event attendance motives and behaviors. First, a frequent motivation to attend an event is for generic leisure and travel, meaning a guest decides to attend an event to feel a sense of escape or fulfillment. This could include reasons such as the destination of the event as an escape from the daily routine, or feeling a sense of fulfillment through learning about or contributing towards the event. Second, individuals may decide to attend because of event-specific characteristics such as location, programming, or good feelings toward the hosting group (e.g. bride and groom at a wedding, or a university holding an alumni event). Finally, Getz and Cheyne point out that motives behind event attendance sometimes have nothing to do with the event itself and instead are due to extrinsic factors that are unrelated to the event. These reasons could include business travel, feelings of obligation, or incentives. Because these motivations are external to the event, this is one dimension that event planners have no control over and cannot therefore use to encourage guest attendance at an event. Although there are many studies that examine motivations behind decisions to attend 
events, the majority of the literature that measures event attendance motivation lies in festival and sporting events research (Abrreau-Novais \& Arcodia, 2013; Petrick, Bennett, \& Tsuji, 2013).

Abrreau-Novais and Arcodia (2013) conducted a meta-analysis of 29 empirical studies related to event attendance motivation across several event types, but primarily focused on festival attendance. From these 29 studies, the factors with the strongest influence on event attendance included socialization, family togetherness, event novelty, escape/relaxation, specific motivators, other motivators, excitement/enjoyment, and cultural activities. Interestingly, philanthropic motivations were missing from this list. The most frequently found motivation to attend an event across the literature was socialization, followed by family togetherness (Abrreau-Novais \& Arcodia, 2013). With this knowledge an event planner would be able to strategically market an event to social groups. Events by nature are social, but an event designed to optimize the social experience may not only increase the likelihood that someone will attend an event, but may also influence that person's loyalty to the organization and decision to return.

University events are unique in that they highlight a particular facet of the university, most often the students. Students often engage in university events as both guests and volunteers. Wakelin (2013) conducted a study to determine the motivations of students to volunteer at an event. Through survey research, Wakelin determined significant motivators that predicted the behavior of volunteering. These included a sense of community, experience, social purposes, a link to the cause, and fun and enjoyment. Most importantly, Wakelin (2013) determined that the majority of these motivations were semi-altruistic. From a practical perspective, an event planner that is 
seeking student volunteers may use this finding to gain a better understanding of what motivates students to volunteer at events. The involvement of students in events is particularly important in a university fundraising setting because guests get to see whom their support is directly impacting. Finally, a university event planner would want to understand if student involvement is a significant predictor in determining a guests overall satisfaction with the event that ultimately encourages university loyalty. Fostering Satisfaction to Encourage Event Loyalty

The literature shows that several tools have been used to measure event satisfaction leading to repeat attendance and event loyalty across many types of events. Most often these are larger scale events, in which individual components are measured. Petrick et al. (2013) argued that satisfaction in these individual experiences relate to event satisfaction, but do not make up the overall satisfaction one feels after an event. Simply put, the whole is not the sum of the parts in the case of events. Petrick et al. created EVENTQUAL, a measurement tool adapted from a service quality index often referred to as SERVQUAL. The purpose of EVENTQUAL is to measure attendee satisfaction of an event, and "to examine the relationships between these evaluations and their overall satisfaction and loyalty” (p. 97). Through this method, the authors supported the earlier work of Crompton and McKay (1997), which found that each element of the event should be evaluated separately. Petrick et al. (2013) also found that overall satisfaction is strongly related to event loyalty. It makes sense that positive and satisfying experiences lead to a desire to repeat those experiences. However, for an events team to be able to encourage these positive experiences leading to event satisfaction, they must understand the aspects of the event that guests value most. 
A multivariable approach to events may build understanding of how perceived value can lead to satisfaction and event loyalty. Yoon et al. (2009) found that event quality dimensions were positively related to value, and that these improved festival loyalty via satisfaction. They also determined several variables that were significant in determining event satisfaction, particularly for a festival, including: program, food, souvenirs, and facilities. Further, Bojanic and Warnick (2012) found that likelihood of repeat attendance is significantly affected by prior attendance, travel distance, and level of purchase decision involvement. This information is directly in line with Cunningham and Kwon's (2003) findings that previous behavior was a significant factor in a decision to attend and that it alone can help predict not just behavioral intent, but actual behavior.

\section{Evaluating Events}

Although various industries have used different approaches to evaluate the overall success of an event, the university environment creates another layer of complexity. Some university events require different tools of assessment, depending on the status of the guests attending the event. For example, an online satisfaction survey emailed to guests following an event may be appropriate for some events, such as an alumni barbeque or a student-run event, but would be considered unacceptable to follow up with presidential-level guests. This differentiation creates an entirely new challenge. In the past, post-event surveys have been the most widely-used method for measuring event effectiveness through “a number of metrics including audience engagement, participation, improved brand perception, and growth in brand loyalty” (Harris, 2009, p. 12). 
Event planners are now beginning to understand the value in receiving feedback from guests during the event itself. However, this formative evaluation approach must be conducted in a way that doesn't create too much bias, which is especially difficult when asking attendees to voluntarily provide feedback while they are still at the event. Berridge (2012) conducted a case study during an event in which five guests provided feedback at several points throughout the event. The idea of receiving consumer feedback while in the middle of the event experience is a relatively new idea with promise. Berridge found that there is often a disconnect in what an event organizer hopes the guest experiences at an event and what the guest actually reports experiencing. He highlights how difficult it is for an organizer to achieve an ideal guest experience for guests throughout the event. The study also reflects how guest experiences during an event may fluctuate depending on the guests and between different time intervals of the event.

Real-time social media applications are becoming increasingly important as "the coffee break is now being recognized as a critical part of an event and not a moment of downtime” (Ashley, p. 11). Conversely, Myong (2006) points to an input-output model for accurately assessing both direct and indirect economic impacts of special events. However, there are issues to address when following this model, including “inherent assumptions, sampling variability, expenditure switching and choice of economic variables” (Myong, p. 83). These event evaluation tools can be used to identify level of satisfaction and likelihood for repeat attendance, and they can also be used to understand why someone may make a charitable contribution at an event and what would make the person want to donate at future events. 
Intention to Donate: A Revised TPB Model

The literature relating the theory of planned behavior to donating intentions suggests a revised model of The Theory of Planned Behavior (Smith \& McSweeney, 2007; van der Linden, 2011). This revised model was examined and later utilized in part of the researcher's proposed model because it was the only literature linking the Theory of Planned Behavior with charitable giving. The revision of the model includes two additional components: moral norms and past behavior. In order to best execute the purpose of the study in exploring the relationship between university events and charitable giving, all variables that previous research hypothesized to be significant in helping explain that relationship were included in this study. Van der Linden measured the moral norm variable through questions related to people feeling a sense of moral obligation to make a charitable contribution to a cause. This was measured through several survey questions using a Likert scale. Four of the six social-psychological variables were significant in predicting behavioral intention to donate: moral norm, past behavior, perceived behavioral control, and attitude.

Although this research was not conducted in a university giving setting, these findings are applicable to university fundraisers. Understanding some of the motivations behind why people choose to make philanthropic gifts are useful to university fundraisers in how they strategically engage their donor prospects. Van der Linden’s (2011) findings are building blocks to connect university events to charitable giving at an event. The study also found that social norms did not explain any of the variance in intention; whereas, moral norms accounted for a significant amount of the overall variance, and were in fact identified as the strongest predictor of charitable giving intentions. The 
growth of the moral norms component in the development of intention to donate is a factor that should be considered when looking specifically at donations that occur through a university event. Although the literature does not yet apply this model to giving at events, this revised theory of planned behavior supports motivations for giving to a university.

This revised theory of planned behavior model has been extremely successful in predicting intention to make a charitable contribution. In this model, moral norms have been identified as the strongest predictor of intention to donate (Smith \& McSweeney, 2007; van der Linden, 2011). The combination of these four variables (attitude, perceived behavioral control, moral norm, and past behavior) as part of this revised model accounted for $70 \%$ of the variance in charitable intent in van der Linden's research.

\section{Charitable Giving in a University Setting: Further Research}

Previous research regarding giving in a university setting can be divided into two categories: motivations to donate to programs and sense of role identity in predicting university giving. Kim, Gibson, \& Ko (2011) investigated the motivational factors for donors that financially support a university performing arts program. Of the several factors studied, the most significant factors that influence people to donate to a particular program were long-term reliability and an increase in quality of life to the community. Although this information is helpful in discussing the relationship between donors and community benefits, this study examining a performing arts center is unique in that this program benefits the entire community and the donor may directly benefit. In most 
instances of university giving, the intent of the donation is to emphasize student success without a focus on community improvement.

McDearmon (2013) and McAlexander, Koenig, \& Schouten (2006) both examined university giving based on the perception of role identity by the donor. McDearmon (2013) assessed how college and university alumni view their role with their alma mater and then followed with how that perception related to behavior and support. The study drew on previous research on alumni in terms of factors contributing to willingness to donate, but there was no evidence to conclude actual alumni opinions, beliefs, and preferences. This raises the question of moral norms expressed in the revised theory of planned behavior research (van der Linden, 2011) and how those play into the perceived alumni role expectations (McDearmon, 2013). McAlexander et al. (2006) investigated how relationships with the university play a role in loyalty-related behaviors, such as planned giving. Most notably they concluded that the opportunity for universities to build lasting relationships with their alumni for future financial support is the strongest while they are still students on campus. This knowledge is crucial in understanding how best to build relationships with students while still on campus and to actually shift the culture of student perceptions of their university while they are enrolled in school. Students can get involved in events, whether as guests or as student volunteers, that give them insight into why alumni or other donors choose to give back to the university and invest in the future of the university. Ultimately, any gift to the university is adding value to the university and in turn adding value to the degree held by alumni of that university. This change in culture could affect moral norms for the students as future alumni, ultimately increasing motivation to and likelihood of contributing to the university. 


\section{University Events and Donation Behavior: A Missing Link}

The theory of planned behavior has been applied across many disciplines and has proven to be applicable to the study of special events and guest behavior. Although there is substantial research on attendance motivation at events such as music festivals and sporting events, there is a gap in the literature where university-sponsored events are concerned. Socialization is the largest attendance motivator at festivals (Abrreau-Novais \& Arcodia, 2013), however, it is important to note that these findings should be tested similarly on events sponsored by a university.

Once a guest does attend an event, it is then important to assess satisfaction in order to foster event loyalty. Researchers have examined this in a number of ways, but not in a university event setting. Further, depending on the relationship guests have with a university, the factors influencing overall event satisfaction may be different among various constituencies because the motivations behind attending a university event may differ depending on that university relationship. Thus, future research should explore the differences in these constituencies and how that translates to event attendance, satisfaction, loyalty, and giving.

Finally, the use of a revised theory of planned behavior model has been effective in helping to predict charitable giving intent (Smith \& McSweeney, 2007; van der Linden, 2011). With support for moral norms as a motivation leading to donations, this factor should be considered in the future of university engagement and development with donors. Although the theory has been applied to giving, and giving has been examined in a university setting, there is a gap in the literature with regards to how university events, 
when done well, can influence the likelihood of gaining donations to the university and how this theoretical model will apply in a university setting.

The literature shows that while there is plenty of research supporting the theory of planned behavior in health and events areas; there is a lack of application and research for this model in a university setting. Further, university events have only recently focused on measuring event satisfaction in pursuit of gaining event loyalty. This could be a significant variable in determining loyalty to an event, and loyalty to the university and intention to donate. The combination of developed event satisfaction measurement tools and a theoretical application of intention to give create a solid foundation for future research in the role of university events in fundraising efforts.

\section{A New Model for University Fundraising through Strategic Events}

The model proposed in this thesis connects university event quality and a predictive donation behavior based on a revised theory of planned behavior model, with the ultimate goal of increasing donation behavior as a result of the quality of an event. This research identifies variables in the planning of a university event that provide the greatest opportunity to maximize guests' loyalty to the university and their donation behavior. This model utilizes an EVENTQUAL scale, developed by Petrick et al. (2013) that is used to “measure event attendee's evaluation of an event and examine the relationship between these evaluations and their overall satisfaction and loyalty” (p. 97). The proposed model combines the overall satisfaction of an event with van der Linden's (2011) revised theory of planned behavior model. Van der Linden (2011) examined six variables in predicting intention to donate to a university. The proposed model introduces a seventh variable, the product of the EVENTQUAL portion, "overall 
satisfaction with event," to determine the statistically significant predictors of intention to donate at an event. Figure 1 shows the proposed model as the combination of event quality measurement and the revised theory of planned behavior for university giving model with the eventual outcome of donation behavior. 


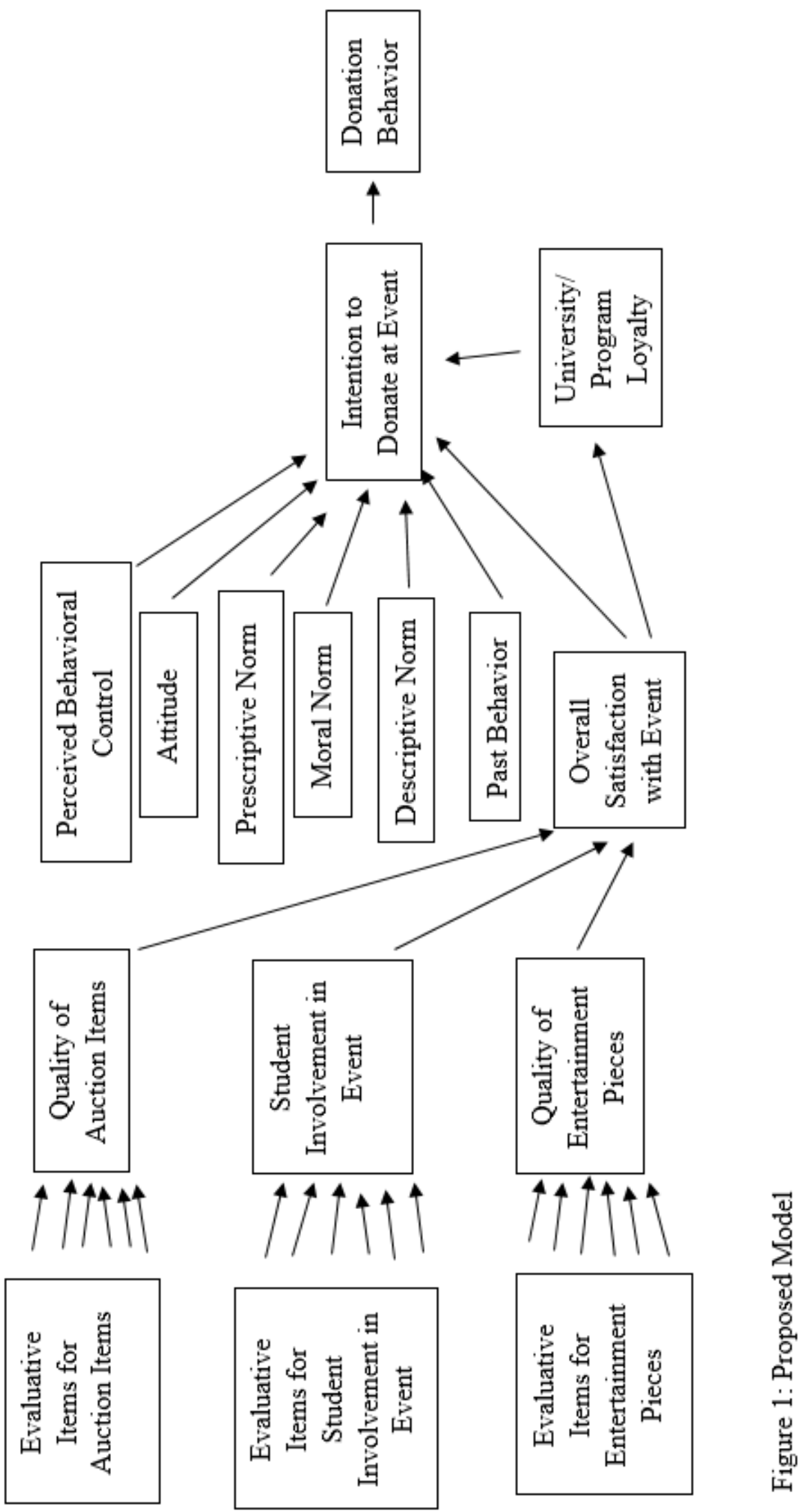




\section{Hypothesis Statements}

The purpose of this study was to apply the Revised Theory of Planned Behavior and EVENTQUAL models to explore (1) event qualities that significantly impact guests’ satisfaction with a university event that they attend, (2) significant factors influencing university loyalty as a result of the event, and (3) willingness to make a charitable donation to a university as a result of attending an event.

This study was conducted to test the following hypotheses:

H1: Evaluative survey items assumed to measure a specific variable will load on the same respective event variable.

H2: The constructs formed by measuring the motivation, importance, quality, value, transaction satisfaction, and word-of-mouth items for the auction items, student involvement, and entertainment pieces, will all be positively and significantly related to overall satisfaction of a university event.

H3: Event attendee’s overall satisfaction will be positively and significantly related to their loyalty to the university event.

H4: Event attendee's loyalty to the university event will be positively and significantly related to their intention to make a charitable gift at that event.

H5: Overall event satisfaction, attitude, perceived behavioral control, prescriptive norm, descriptive norm, moral norm, and past behavior will be positively and significantly related to intention to make a charitable gift at a university event.

H6: Intention to donate will be a significant predictor in determining whether a guest makes a charitable gift at a university event. 


\section{Summary}

This chapter outlined the current literature on the application of the Theory of Planned Behavior, specifically relating to charitable giving and EVENTQUAL, a tool for measuring event quality. The purpose of this study is to test a series of hypotheses to establish a new model that bridges this research gap in event quality measurement and charitable giving intent specifically in a university setting. The chapter to follow will discuss the methods by which the researcher will test this series of hypotheses. 


\section{CHAPTER 3}

\section{METHODS}

This chapter explains the setting, subjects, instrument design, pilot study, data collection procedures, and data analysis of this study. The purpose of this study was to apply the Revised Theory of Planned Behavior and EVENTQUAL models to explore (1) event qualities that significantly impact guests' satisfaction with a university event that they attend, (2) significant factors influencing university loyalty as a result of the event, and (3) willingness to make a charitable donation to a university as a result of attending an event.

Setting

The Recreation, Parks, and Tourism Administration (RPTA) department at California Polytechnic State University, San Luis Obispo, holds an annual auction and dinner event to raise funds for the department. The event is planned throughout the course of a year by a committee of undergraduate students, under the leadership of either a faculty member or a graduate student. Each year, these students solicit donations from members of the community, alumni, and friends of the department. These items are then auctioned off at the event in either a silent or live auction, with proceeds directly benefitting the students of the RPTA department. In addition to the auction items, this event includes various entertainment elements ranging from a DJ and live music to social media contests and photo booths. Every aspect of the event, from registration to marketing pieces, overall branding, check out service, and auction runners are student volunteers visible to event attendees as they work to execute the event. 


\section{Subjects}

The survey (Appendix A), created with the online survey generator surveymonkey.com, was emailed to all past attendees of the RPTA auction and dinner event in February of 2016. These guests were divided into five guest types: student, alumna/alumnus, parent of student, faculty/staff, and university supporter.

For this analysis, 530 unique email addresses were obtained from the department's event registration records from 2002-2015. Of those 530 emailed to, 98 were returned as invalid email addresses, decreasing RPTA attendees that received the survey via email to 432 . The email was sent by the researcher and is provided as Appendix B. Due to the fact that the event registration page only collected the email address for the orderee, the link to the online survey was also promoted through the Cal Poly RPTA department Facebook page. Due to a small response rate from the initial email, the 2016 RPTA auction event (that occurred on February 27, 2016) brought in an additional 106 email addresses that received the email with survey link in March 2016. This brought the target sample size to 538 valid email addresses and any additional Facebook page traffic.

Instrument Design

A survey was used to collect quantitative data and to measure the event attributes that influence the overall satisfaction of the event for Cal Poly RPTA auction event attendees. Further, the survey was also used to determine if an event attendee's overall satisfaction influenced event loyalty, and subsequently, influenced charitable giving at the event. This survey was adapted from a combination of two conceptual models. First, this study utilized an EVENTQUAL scale, developed by Petrick, et al. (2013). The 
purpose of EVENTQUAL is to “measure event attendee’s evaluation of an event and examine the relationship between these evaluations and their overall satisfaction and loyalty” (Petrick et al., p. 97). Second, the study used a revised theory of planned behavior model developed by van der Linden (2011) to examine charitable giving habits of event attendees.

The specific questions used in the survey were adapted from previous literature. For the EVENTQUAL items, the survey follows the layout proposed by Petrick, et al. (2013). The survey looks at three particular event structures, as in previous EVENTQUAL research (Petrick et al.). These three structures included (1) auction items (live and silent auction items), (2) involvement of students (level of involvement in guest's event experience), and (3) entertainment pieces (DJ, live music, photo booths, social media content, etc.) at the event. These three structures were identified by the researcher as variables that an event planner could manipulate during the initial event planning in order to maximize guests overall loyalty to the university. For each of the three event structures, six questions were asked reflecting motivation, importance, quality, perception of value, transaction satisfaction, and word of mouth. Overall event satisfaction and loyalty to organization were measured with an additional three and five questions, respectively. In following previous EVENTQUAL model protocol, all of the items were measured on a 7-point scale ranging from "strongly disagree" to "strongly agree." These variables together comprise the EVENTQUAL portion of the proposed new model. The revised theory of planned behavior model was taken into account to reflect giving behavior and is addressed in the upcoming questions. 
The revised theory of planned behavior as a predictor of charitable intent was proposed by van der Linden (2011) and is the basis of the latter portion of the proposed model. Each of the six proposed predictors of intention to donate were reflected in one or two questions each and followed the contextual wording proposed by van der Linden (2011). Each was measured on a 7-point scale that vary in anchors but were tested in previous studies. Attitude was assessed with the statement, "making a charitable donation to Cal Poly at the next year's auction event would be," followed by a 7-point scale ranging from "pointless" to "worthwhile." T he perceived behavioral control variable was reflected in questions asking about control over donation behavior and decision to donate. The prescriptive norm variable was determined by questions asking about expectation to make a donation at these events and if a significant other would approve of making a donation at the event. The descriptive norm variable was examined with a question asking "how likely do you think people close to you would make a charitable donation at the auction event," with a 7-point scale ranging from "very unlikely" to "very likely." Moral norm was measured through a question asking about feeling of moral obligation to donate. A question reflecting the past behavior variable asked how often the guest had donated money to Cal Poly, ranging from "not at all" to "very frequently." The behavioral intention variable was measured on a scale of "strongly agree" to "strongly disagree" with the statement "I intend to make a charitable donation to Cal Poly at the auction event in the future." Finally, to determine if a guest had in fact made a donation to Cal Poly, the final content survey question ranged from "strongly disagree" to "strongly agree" with the statement "I have made a significant donation to Cal Poly at the auction event." Van der Linden (2011) utilized multiple 
survey questions for each of the six revised theory of planned behavior predictors. For this survey, these questions were decreased to one or two per variable to preserve the length of the survey.

The survey concluded with questions regarding demographics including age, gender, relationship to Cal Poly (student, parent/supporter, alumni, friend), and annual household income bracket.

\section{Pilot Study}

A pilot study was conducted to assess face validity, the length of time to complete the survey, and an understanding of the questions by the subjects completing the survey. The survey was administered by the researcher to 10 previous event attendees. The participants commented that on average the survey took approximately 3-5 minutes to complete, information that was then added to the initial consent page. Other comments included changing verbage to remain consistent in how the event was referred to, changing all to "RPTA auction.” Pilot study respondents also noted that the "Giving to Cal Poly" portion may be confusing, and suggested adding in "in the future" to some questions to clarify. All of these changes were taken into consideration and after consulting the graduate thesis committee, most changes were made to the survey before it was sent to RPTA auction attendees.

\section{Data Collection Procedures}

The content of the survey was approved by the researcher's thesis committee. Following approval from the California Polytechnic State University Human Subjects Committee, the link to the online survey with the online informed consent letter (Appendix C) was emailed to 538 email addresses provided by RPTA. In addition, the 
link to the online survey was posted on the Cal Poly RPTA department Facebook page and RPTA Auction event page in February 2016. The survey was open for 4 weeks before collecting data from the online survey resource.

\section{Data Analysis}

Following the completion of data collection, data were exported as an SPSS file from the online survey generator, SurveyMonkey. The data analysis for this study used SPSS statistical software. First, an exploratory factor analysis was conducted to structure the evaluative items to test the first hypothesis to confirm that all questions assumed to load on the same factor significantly do so. Then, a series of simple and multiple regression equations were utilized in an effort to determine which variables assumed to function as dependent variables in the proposed model were functioning as significant predictor variables. Next, hierarchical multiple regression analysis was employed to further analyze the combination of variables in each column of the proposed model. Finally, multiple regression analysis was used to pull together the results of all previous hypotheses to determine if the proposed model was a good fit or to develop a revised event fundraising model.

\section{Summary}

An online survey based on a new proposed model combining EVENTQUAL and a revised theory of planned behavior was used to measure (1) event qualities that significantly impact guests' satisfaction with a university event that they attend, (2) significant factors influencing university loyalty as a result of the event, and (3) willingness to make a charitable donation to a university as a result of attending an event. A pilot study was conducted to assess any item ambiguity in wording and to determine a 
time estimate for completing the survey. This survey was emailed to attendees of an annual department auction event (2002-2016) at California Polytechnic State University, San Luis Obispo, in February of 2016. Attendees of the 2016 event received the survey email in March 2016 as the 2016 event was held on February 28, 2016. The results of the survey and analysis of the proposed model will be discussed in the next chapter. 


\section{CHAPTER 4}

\section{RESULTS}

This chapter outlines the survey results in order to test the proposed model. The purpose of this study was to apply the Revised Theory of Planned Behavior and EVENTQUAL models to explore (1) event qualities that significantly impact guests’ satisfaction with a university event that they attend, (2) significant factors influencing university loyalty as a result of the event, and (3) willingness to make a charitable donation to a university as a result of attending an event. This chapter presents the results of the survey.

\section{Initial Data Cleaning}

One hundred and seven total responses were collected via the online survey link. After deleting 29 responses that did not provide data beyond agreeing to take the survey (respondent closed out of the survey after question 1), the sample size decreased to 78 respondents. Respondents who left more than three questions blank (more than $10 \%$ of the 36 question survey) were removed, leaving a sample size of 74 . One of the respondents answered all but two questions, and two more respondents answered all but one question. Coincidentally, none of these four missing data points were for the same question. Since this missing data accounted for less than five percent of the total responses for each question, a mean imputation method was used to estimate those four data points and a sample size of 74 . 


\section{Respondent Demographics}

Of the 74 respondents, the majority were female (52 female, 22 male). The mean age was 42 years old, with 37.5\% between the ages of 40 and $60(n=27)$ and 31\% between the ages of 26 and $40(n=22)$ (Table 1). Many of the respondents reported more than one category as their relationship to Cal Poly. Respondents reported their relationships with Cal Poly, with 54\% identifying as alumni (n=40) and 24\% identifying as a Cal Poly parent $(n=18)$ (Table 2). With regard to income, 23\% reported income between $\$ 100,000$ and $\$ 150,000(n=17)$, and 28\% reported income of over $\$ 150,000$ $(n=21)$ (Table 3). When asked to provide graduation major and year, only 47 respondents provided an answer. Of these 47 respondents, $74 \%$ of them $(n=35)$ were graduates of the Recreation, Parks, and Tourism Administration major. The other 26\% $(n=12)$ listed a different degree.

Table 1

Age

\begin{tabular}{lccc}
\hline Age & Frequency & Percentage & Cumulative \% \\
\hline $18-25$ years old & 14 & 19.44 & 19.44 \\
$26-40$ years old & 22 & 30.55 & 49.99 \\
$41-60$ years old & 27 & 37.50 & 87.49 \\
Over 60 years old & 9 & 12.50 & 99.99 \\
\hline
\end{tabular}

Note. $\mathrm{n}=72$ 
Table 2

Relationship to Cal Poly

\begin{tabular}{lcc}
\hline Education & Frequency & Percentage \\
\hline Student & 7 & 9.45 \\
Alumni & 40 & 54.05 \\
Parent & 18 & 24.32 \\
Faculty/Staff & 8 & 10.81 \\
Supporter & 10 & 13.51 \\
\hline
\end{tabular}

Note. $\mathrm{n}=74$, Guests could choose more than one relationship to Cal Poly

Table 3

Annual Household Income

\begin{tabular}{lccc}
\hline Income & Frequency & Percentage & Cumulative \% \\
\hline Greater than $\$ 150,000$ & 21 & 29.58 & 29.58 \\
$\$ 100,000-150,000$ & 17 & 23.94 & 53.52 \\
$\$ 75,000-99,999$ & 6 & 8.45 & 61.97 \\
$\$ 50,000-74,999$ & 12 & 16.90 & 78.87 \\
$\$ 35,000-49,999$ & 6 & 8.45 & 87.32 \\
$\$ 20,000-34,999$ & 6 & 8.45 & 95.77 \\
Less than $\$ 20,000$ & 3 & 4.22 & 99.99 \\
\hline
\end{tabular}

Note. $\mathrm{n}=71$

Proposed Model Analyses

The researcher employed two different statistical analysis methods to test the proposed model (Figure 1). The first hypothesis was tested through a series of exploratory factor analyses, broken down into five different tests. The purpose of this procedure was to consolidate questions that were assumed to be measuring the same 
construct by creating an aggregate variable. The event quality variables: Auction Items, Student Involvement, and Entertainment were examined in H1a to reduce the six questions reflecting each into one variable. The researcher then conducted exploratory factor analyses (EFA) on the following variables separately to confirm the ability to consolidate multiple survey questions into one variable each: Event Satisfaction, Loyalty, Perceived Behavioral Control, and Prescriptive Norm. Based on the results of the EFA, if all questions that were assumed to load onto the same factor did in fact do so, they were averaged so that each construct was measured with one aggregate score. Once all of the questions were reduced to the 13 variables reflected in the proposed behavioral model, a series of statistical regression models, outlined later in the chapter, were tested in consultation with pairwise correlations. To address hypotheses 2 through 6 , regression analysis and hierarchical regression analysis were used to determine which variables were significant in predicting a series of dependent variables, as outlined in Figure 1. The researcher used SPSS statistical software (23) and concluded a variable to be statistically significant if it had a p-value of less than 0.05 .

\section{Exploratory Factor Analyses: Consolidating Variables}

Exploratory factor analyses were used to simplify variables measured by more than one survey item into one variable. First, in the measurement of the three event attributes (Auction Items, Student Involvement, and Entertainment), the researcher followed the work of Petrick et al. (2013) to consolidate responses into one variable for further model validity testing in combination of additional variables adapted from a revised theory of planned behavior. 
The researcher checked the factor loading to be sure the hypothesized related questions were in fact measuring the same thing. A series of new hypotheses were tested to confirm this consolidation at each level of the EVENTQUAL measurement process (3 event attributes, event satisfaction, and event loyalty):

H1a: Auction items, student involvement, and entertainment pieces load on independent factors

H1b: All 3 questions that the researcher assumed related to satisfaction, load on one factor

H1c: All 5 loyalty questions load on one factor

H1d: Both Perceived Behavioral Control questions load onto one factor H1e: Both Prescriptive Norm questions load onto one factor

To test H1a, an exploratory factor analysis with orthogonal rotation of the 18 evaluation items related to event quality items revealed a four-factor solution with eigenvalues greater than 1 . However, after a parallel analysis and an examination of the scree plot, it was determined that only three factors should be retained. These three factors explain $68.9 \%$ of the variance (34.5\%, $20.0 \%$, and $14.3 \%$ respectively) and were named: Entertainment, Student Involvement, and Auction Items. As hypothesized, each of the evaluative items loaded on the attraction they were measuring, and not with items that have historically been considered similar. Additionally, the alpha coefficients for all three factors were high $(.93, .89$, and .87 respectively). Thus, H1a was confirmed and the six items measuring each construct were averaged into one score. 
To test H1b, an exploratory factor analysis confirmed that the three questions assumed to represent an event attendee's satisfaction did in fact load on the same factor. These three variables together explain approximately $75 \%$ of the variance in predicting overall event satisfaction, with an alpha of .81 (Table 4). Therefore, the variables were averaged for each individual to create one overall satisfaction variable.

To test H1c, an exploratory factor analysis confirmed that the five questions assumed to represent event attendee loyalty did in fact load on the same factor. These 5 variables together explain $63.5 \%$ of the variance in predicting overall loyalty, with an alpha of .85 (Table 4). Therefore, these items were averaged for each individual to create one loyalty variable.

To test H1d, an exploratory factor analysis confirmed that the two questions assumed to represent an event attendee's perceived behavioral control did in fact load on the same factor. These 2 variables together explain approximately $71 \%$ of the variance in predicting perceived behavioral control, with an alpha of .59 (Table 4). Therefore, these two questions were averaged for each individual to create one perceived behavioral control variable.

To test H1e, an exploratory factor analysis failed to confirm that the two questions represented an event attendee's prescriptive norm.

Largely based on the small sample size, the researcher could not find evidence to support that there is a significant correlation between the two questions intended to measure the prescriptive norm variable. These questions asked the subject if they felt expected to make a donation at the event and if their significant others would approve of them making such a donation. However, van der Linden (2011) recognized that while 
these questions are both measuring explicit social pressure, one focused more on the external approval of behavior. Although it is not surprising that these two items were not significantly correlated, they still both measured the Prescriptive Norm variable. Despite the fact that these did not load on the same factor, van der Linden (2011) averaged 3 question responses to describe an index of the norm. Van der Linden (2011) noted that excluding the perceived approval measure "significant others would approve of me donating...” did increase the reliability score. Despite the fact that these two questions did not load on the same factor the researcher followed van der Linden's example, averaging the responses from the 2 prescriptive norm questions to provide an index of the Prescriptive Norm.

After consideration by the researcher and graduate thesis committee, it was agreed that the survey question intended to measure donation behavior was set up in a manner that likely seemed to the respondent to instead measure past behavior. The question itself read "I have made a significant donation to Cal Poly at the RPTA auction", however, the heading above the question was titled "Past Giving." An exploratory factor analysis confirmed that both the past behavior question and the intended donation behavior question measured the same thing. Therefore, these were averaged into the "Past Behavior" variable, eliminating the donation behavior variable from the model entirely. As a result, the sixth initial hypothesis of this research was removed because "donation behavior" was no longer included in the model. The model that was tested ended with the variable, Intention to Donate. 
Table 4

Factor Analysis of Variables Examined in H1 Hypotheses

\begin{tabular}{|c|c|c|c|}
\hline Domains & $\begin{array}{l}\text { Factor } \\
\text { Loadings } \\
\end{array}$ & Eigenvalue & $\begin{array}{l}\text { Variance } \\
\text { Explained }\end{array}$ \\
\hline \multicolumn{4}{|c|}{ Entertainment components on quality of event (H1a) } \\
\hline Recommend to friends & 0.79 & & \\
\hline Arrive early for & 0.73 & & \\
\hline Significantly effects overall experience & 0.83 & & \\
\hline Quality component of event & 0.78 & & \\
\hline Adds value to event & 0.69 & & \\
\hline Influenced attendance & 0.72 & & \\
\hline \multicolumn{4}{|l|}{ Entertainment alpha $=.93$} \\
\hline \multicolumn{4}{|l|}{ Auction items on quality of event (H1a) } \\
\hline Recommend to friends & 0.9 & & \\
\hline Arrive early for & 0.88 & & \\
\hline Significantly effects overall experience & 0.87 & & \\
\hline Quality component of event & 0.84 & & \\
\hline Add value to event & 0.84 & & \\
\hline Influenced attendance & 0.78 & & \\
\hline \multicolumn{4}{|l|}{ Auction items alpha $=.86$} \\
\hline \multicolumn{4}{|l|}{ Student Involvement on quality of event (H1a) } \\
\hline Recommend to friends & 0.62 & & \\
\hline Arrive early for & 0.65 & & \\
\hline Significantly effects overall experience & 0.86 & & \\
\hline Quality component of event & 0.81 & & \\
\hline Adds value to event & 0.77 & & \\
\hline Influenced attendance & 0.67 & & \\
\hline $\mathrm{H} 1 \mathrm{a} \alpha=.85$ & & 2.73 & 65.16 \\
\hline \multicolumn{4}{|l|}{ Event Satisfaction (H1b) } \\
\hline One of the best events attended & 0.75 & & \\
\hline Satisfied with decision to attend & 0.90 & & \\
\hline Truly enjoyed event & 0.93 & & \\
\hline $\mathrm{H} 1 \mathrm{~b} \alpha=.81$ & & 2.25 & 74.99 \\
\hline \multicolumn{4}{|l|}{ Loyalty (H1c) } \\
\hline Loyal attendee of event & 0.79 & & \\
\hline Encourage friends to attend & 0.67 & & \\
\hline Will attend in future & 0.83 & & \\
\hline Supporting event important & 0.93 & & \\
\hline Supporting organization important & 0.74 & & \\
\hline $\mathrm{H} 1 \mathrm{c} \alpha=.85$ & & 3.18 & 63.53 \\
\hline \multicolumn{4}{|l|}{ Perceived Behavioral Control (H1d) } \\
\hline Overall donation control & 0.84 & & \\
\hline Future donations individual decision & 0.84 & & \\
\hline $\mathrm{H} 1 \mathrm{~d} \alpha=.59$ & & 1.42 & 70.99 \\
\hline \multicolumn{4}{|l|}{ Prescriptive Norm (H1e) } \\
\hline Perceived expectation to donate & 0.76 & & \\
\hline Significant others would approve donation & 0.76 & & \\
\hline H1e $\alpha=.29$ & & 1.16 & 58.42 \\
\hline
\end{tabular}


Simple Linear, Multiple, and Hierarchical Regression Analyses

Table 5 outlines the descriptive statistics and intercorrelations for the 12 proposed model variables. Notably, attitude was highly correlated with loyalty (0.63), intention to donate (0.65), and Perceived Behavioral Control (0.50). Additionally, intention to donate and loyalty were highly correlated (0.67). Prescriptive Norm was also highly correlated with Moral Norm (0.54), Intention to Donate (0.57), and Loyalty (0.53). Guests who intend to donate were extremely influenced by their attitude to do so.

The researcher tested the validity of the proposed theoretical model through a series of simple regression analyses (hypotheses 2-4). The first regression (H2) examined how auction items, student involvement, and entertainment predict the dependent variable, overall satisfaction. Next, to test the third hypothesis, the researcher used simple regression analysis to determine if overall event satisfaction is a significant predictor of university loyalty. Then, the fourth hypothesis was tested to determine if loyalty predicts intention to donate, again through simple regression analysis. Finally, through the use of a hierarchical multiple regression analysis, the combination of all six revised theory of planned behavior variables (perceived behavioral control, attitude, prescriptive norm, descriptive norm, and past behavior) along with the new EVENTQUAL variable, overall event satisfaction, was regressed on intention to donate to determine which variables contribute to a guest's intention to donate at a university event. 


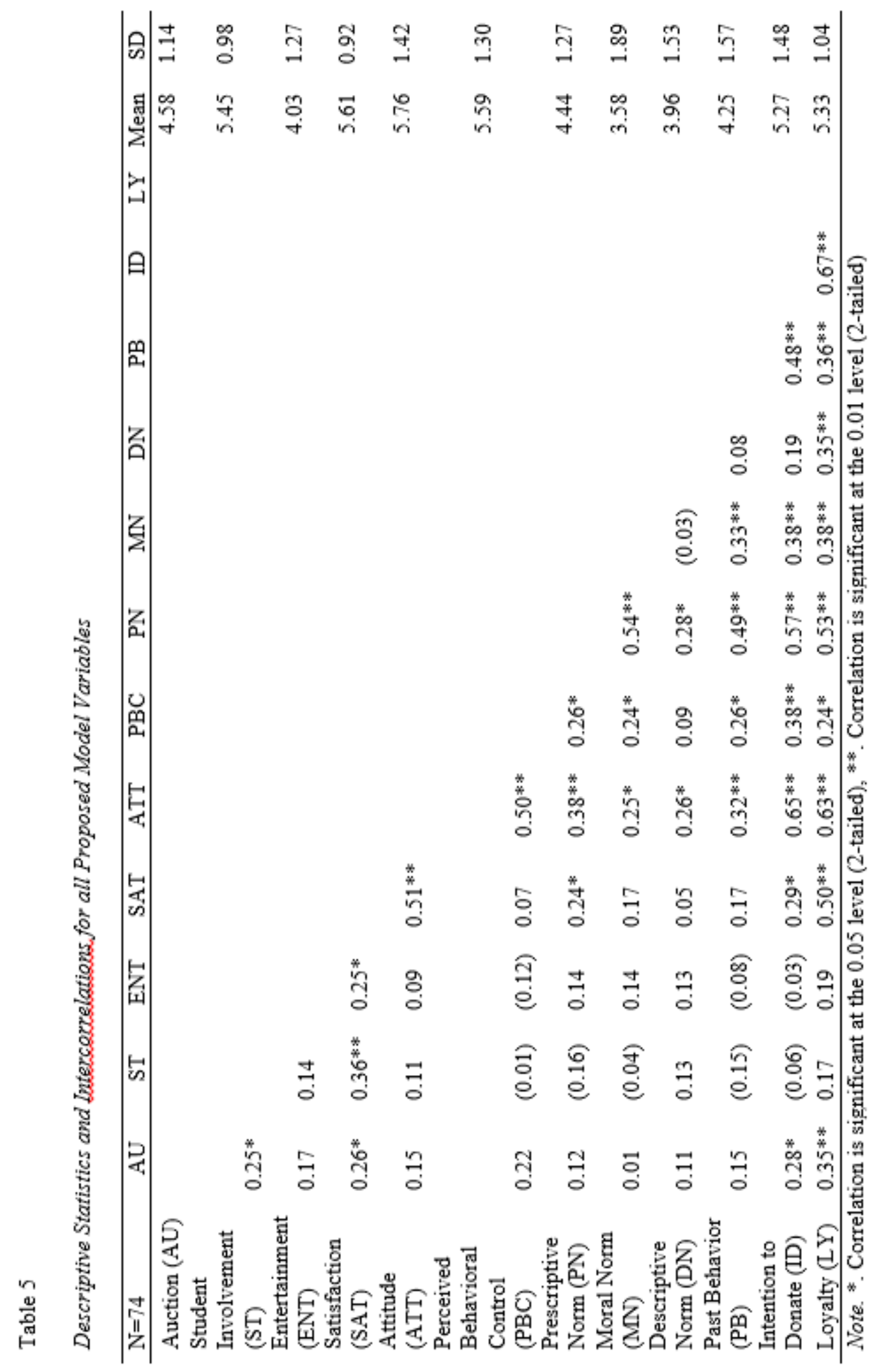




\section{Predicting Overall Satisfaction}

H2: The constructs formed by measuring the motivation, importance, quality, value, transaction satisfaction, and word-of-mouth items for the auction items, student involvement, and entertainment pieces, were positively and significantly related to overall satisfaction of a university event.

To measure this hypothesis, the three event attributes were regressed on the dependent variable, overall satisfaction. This hypothesis was rejected as only Student Involvement was significant at an alpha level of 0.05 in predicting overall satisfaction with an event (Table 6).

Table 6

Coefficients in Predicting Overall Satisfaction

\begin{tabular}{lccccc}
\hline & \multicolumn{2}{c}{$\begin{array}{l}\text { Unstandardized } \\
\text { Coefficients }\end{array}$} & $\begin{array}{l}\text { Standardized } \\
\text { Coefficients }\end{array}$ & & \\
Model & $\mathrm{B}$ & Std. Error & Beta & $\mathrm{t}$ & $\mathrm{p}$ \\
\hline (Constant) & 3.01 & 0.65 & & 4.67 & 0 \\
Auction Items & 0.12 & 0.09 & 0.15 & 1.36 & 0.18 \\
Student & & & & & \\
Involvement & 0.28 & 0.1 & 0.3 & 2.37 & 0.01 \\
Entertainment & 0.13 & 0.08 & 0.18 & 1.66 & 0.1 \\
\hline
\end{tabular}

Note. Dependent Variable: Satisfaction

Quality of auction items and entertainment pieces were not significant predictors of overall event satisfaction and were therefore removed from the proposed model. Predicting Loyalty

H3: Event attendee's overall satisfaction was positively and significantly related to their loyalty to the university event. 
This hypothesis was confirmed, overall satisfaction is a significant, positive predictor of loyalty (Table 7 ). The adjusted R-squared value suggests that $23.6 \%$ of the variance in loyalty can be explained by overall satisfaction.

Table 7

Coefficients in Predicting University Loyalty

\begin{tabular}{lccccc}
\hline & \multicolumn{2}{c}{ Unstandardized } & & & \\
Model & \multicolumn{2}{c}{ Coefficients } & $\begin{array}{l}\text { Standardized } \\
\text { Coefficients }\end{array}$ & & \\
\hline (Constant) & B & Std. Error & Beta & t & p \\
Satisfaction & 2.17 & 0.66 & & 3.29 & 0.002 \\
\hline
\end{tabular}

Note. Dependent Variable: University Loyalty

\section{Predicting Intention to Donate}

H4: Event attendee’s loyalty to the university event will be positively and significantly related to their intention to make a charitable gift at that event.

This hypothesis was confirmed. Loyalty was a significant, positive predictor of intention to make a charitable donation at an event (Table 8). The adjusted R-squared value suggests that $43.8 \%$ of the variance in intention to donate can be predicted by loyalty.

Table 8

Coefficients in Predicting Intention to Donate through Loyalty

\begin{tabular}{lccccc}
\hline & \multicolumn{2}{c}{$\begin{array}{l}\text { Unstandardized } \\
\text { Coefficients }\end{array}$} & $\begin{array}{c}\text { Standardized } \\
\text { Coefficients }\end{array}$ & & \\
Model & $\mathrm{B}$ & Std. Error & Beta & $\mathrm{t}$ & $\mathrm{p}$ \\
\hline (Constant) & 0.18 & 0.68 & & 0.27 & 0.79 \\
Loyalty & 0.96 & 0.13 & 0.67 & 7.61 & 0.00 \\
\hline
\end{tabular}

Note. Dependent Variable: Intention to Donate 


\section{Hierarchical Multiple Regression}

A hierarchical regression analysis was employed to examine the revised theory of planned behavior (van der Linden, 2011) portion of the proposed model including the addition of overall satisfaction with the event. This tested H5, the hypothesis that overall satisfaction with event, attitude, perceived behavioral control, prescriptive norm, descriptive norm, moral norm, and past behavior were positively and significantly related to intention to make a charitable gift at a university event. This analysis was divided into three statistical models with results provided in Table 9.

Table 9

Hierarchical Multiple Regression

\begin{tabular}{lllll}
\hline Intention to Donate & Model (1) & Model (2) & Model (3) & Model (4) \\
& $\beta$ & $\beta$ & $\beta$ & $\beta$ \\
\hline Attitude & $0.55^{* * *}$ & $0.61^{* * *}$ & $0.52^{* * *}$ & $0.37^{* *}$ \\
Perceived Behavioral & & & - & - \\
Control & 0.01 & - & - & - \\
Moral Norm & 0.13 & - & - & - \\
Past Behavior & $0.24^{* *}$ & $0.23^{* *}$ & 0.12 & - \\
Satisfaction & & $(0.09)$ & - & $0.33^{* *}$ \\
Prescriptive Norm & & & $0.39 * *$ & - \\
Descriptive Norm & & & $(0.05)$ & $0.42^{* *}$ \\
Loyalty & & & & 74 \\
N & 74 & 74 & 74 & 0.57 \\
Adj. R & & 0.46 & 0.53 & 0.04 \\
$\Delta$ Adj. R & 0.50 & $(0.04)$ & 0.09 & 33.25 \\
F & & 22.08 & 21.89 &
\end{tabular}

Note. Standardized beta coefficients; ${ }^{*} \mathrm{p}<0.05$, ${ }^{*}{ }^{*} \mathrm{p}<0.01$, $* * * \mathrm{p}<0.0001$ 
Model 1: Revised theory of planned behavior variables (van der Linden, 2011) research on predicting intention to donate (attitude, perceived behavioral control, moral norm, and past behavior). In Model 1, attitude and past behavior were significant at the alpha of 0.05 level. However, perceived behavioral control and moral norm were not, and therefore were not included in Model 2.

Model 2: Attitude, Moral Norm, Past Behavior and Overall Satisfaction on predicting Intention to Donate. In this model, overall satisfaction was included to add the EVENTQUAL construct to the revised theory of planned behavior model. In Model 2 once again only attitude and past behavior were significant in predicting intention to donate, while overall satisfaction was insignificant. As a result, overall satisfaction was not included in Model 3.

Model 3: Attitude, Past Behavior, Prescriptive Norm, and Descriptive Norm in predicting Intention to Donate. In Model 3, only attitude and prescriptive norm were significant in predicting intention to donate, with past behavior and descriptive norm as insignificant predictor variables. Together, attitude and prescriptive norm provide the best fit model, explaining 53\% of the variance in predicting intention to donate.

While Model 3 finalizes the validity of the satisfaction and revised theory of planned behavior variables in predicting intention to donate, the initial model proposes that intention to donate is predicted by these seven tested variables and an additional variable: loyalty. To take the analysis a step further, the researcher tested a fourth model, including the two significant predictors that came out of Model 3 (testing H5) and loyalty, which proved to be a significant predictor of intention to donate when testing this as the previous hypothesis (H4). The result (Model 4) was an even stronger model in 
predicting intention to donate. Together, attitude, prescriptive norm, and loyalty explain $57 \%$ of the variance with an F-value of 33.25, a much better fit model than statistical Models 1, 2, or 3. The progression of models 1-4 are outlined in Table 9.

This analysis, in combination with the results of the simple and multiple regression analyses testing hypotheses 2-4, concludes the analysis of the researcher's proposed model.

\section{The Proposed Model}

Figure 2 outlines the results of the series of hypotheses presented in this research to test the proposed model. Donation Behavior was removed from the model entirely due to previously mentioned survey wording confusion. Therefore, the proposed model's end result would hope to predict intention to donate. While all 12 valid variables are still shown, only the significant relationships remain connected, with their beta coefficients and significance levels coded. Student Involvement, the only significant predictor of Overall Satisfaction as a result of hypothesis 2, was regressed again on Overall Satisfaction without the insignificant Auction Items and Entertainment variables in order to determine the updated significant coefficient, reported in Figure 2. As a result of hypothesis 3, Overall Satisfaction was a strongly significant predictor of University Loyalty, reflected in the Proposed Model Results. Finally, the results of testing H4 and H5 are reported in Figure 2 as the coefficients and significance levels of the combined model fit of Attitude, Prescriptive Norm, and University Loyalty as significant predictors of Intention to Donate. 


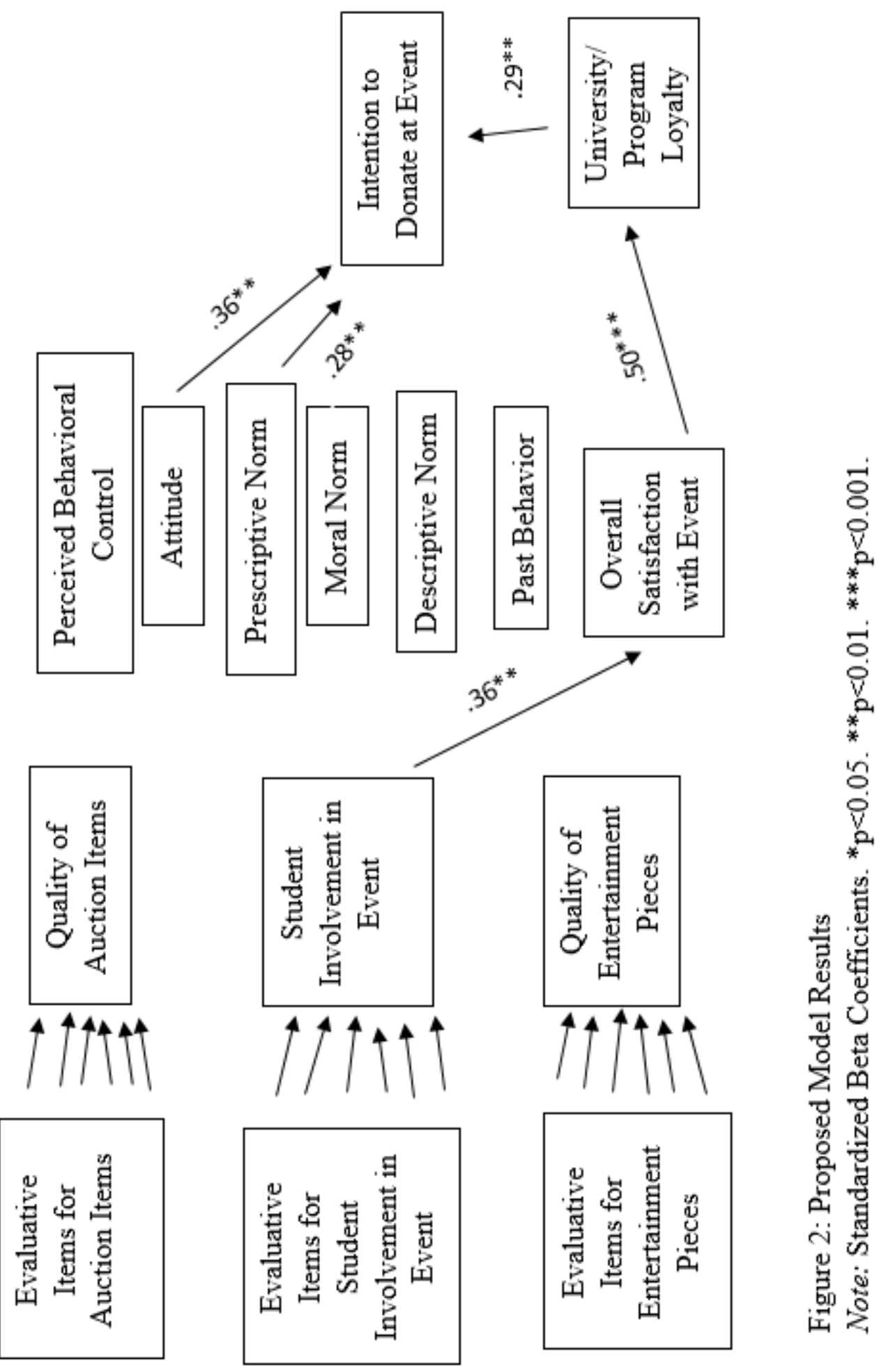


Prior to any data analysis, the researcher knew that analyzing 13 variables with a small sample size may not be able to examine the fit of such a large model. The proposed model was a combination of two separate models put together and connected by overall event satisfaction. In reality, the EVENTQUAL and Revised Theory of Planned Behavior Models have variables that are much more intertwined. The initial proposed model was a first attempt to understand how these variables might interact. However, it became apparent that the results of the proposed model in Figure 2 did not fully represent the relationships between these variables and a better model, with valuable practical implications, may exist. his conclusion prompted the development of a revised model. Predicting Charitable Giving at a University Event: A Revised Model

The need for the development of a new revised model became clear based on the results of the hierarchical multiple regression. The focus of the proposed model was primarily on the Intention to Donate variable. However, the ability to predict and therefore influence university loyalty, a variable that itself is significant in predicting intention to donate, seemed to be a logical next direction for analysis. Additionally, even if a guest does not intend to donate at a university event, the person can still become a loyal attendee of the event. A guest's intention to return to the event gives planners that opportunity to influence attitude, prescriptive norms, or loyalty, which can increase the chances of that guest intending to donate at a future time. In short, the loyalty variable was perhaps not as prominent in the original proposed model as it should have been, especially given its prominence as one of three parts to the initial purpose of this study.

In an effort to explore the relationships between all revised theory of planned behavior and event satisfaction variables, a backward selection for a reduced and 
significant model was used to determine the best model in predicting University Loyalty. All six Revised Theory of Planned Behavior variables and Overall Event Satisfaction was regressed on University Loyalty. After running the full statistical model with all seven variables, Past Behavior had the largest insignificant p-value (.51) and was removed. The regression was rerun without Past Behavior. With six predictor variables, Perceived Behavior Control became the next variable discarded for its insignificant p-value (.38). After a regression of the five remaining variables, Prescriptive Norm was discarded although it was just barely insignificant at the .05 level with a p-value of 0.053 .

The four remaining variables, Attitude, Overall Event Satisfaction, Descriptive Norm, and Moral Norm were all significant in predicting University Loyalty with an adjusted R-squared of 0.51 . The results of this regression are outlined in Table 10.

Table 10 Coefficients in Predicting University/Program Loyalty, Full Model

\begin{tabular}{lccccc}
\hline & \multicolumn{2}{c}{$\begin{array}{l}\text { Unstandardized } \\
\text { Coefficients }\end{array}$} & $\begin{array}{l}\text { Standardized } \\
\text { Coefficients }\end{array}$ & \\
& & Std. & & \\
Model & B & Error & Beta & t & p \\
\hline (Constant) & 1.01 & 0.57 & & 1.78 & 0.08 \\
Attitude & 0.28 & 0.07 & 0.38 & 3.79 & 0.00 \\
Moral Norm & 0.14 & 0.05 & 0.25 & 2.89 & 0.00 \\
Descriptive Norm & 0.16 & 0.06 & 0.24 & 2.83 & 0.01 \\
Overall Satisfaction & 0.28 & 0.11 & 0.25 & 2.60 & 0.01
\end{tabular}

Note. Dependent Variable: University/Program Loyalty

With the findings of the reduced significant model in predicting University Loyalty, a revised model was developed to summarize the overall findings of this study 
and to give a quick snapshot of the relationships between measured variables, shown in Figure 3.

The revised model is essentially a series of three regression equations, focusing on the following dependent variables: overall satisfaction, university loyalty, and intention to donate. In total, four variables were removed entirely: auction items, entertainment, past behavior, and perceived behavioral control. Auction items and entertainment were not significant predictors of overall satisfaction and did not improve the model in predicting overall event satisfaction. Past behavior and perceived behavioral control did not contribute to the models predicting either loyalty or intention to donate.

The following equations together create the most significant model based on the tested variables:

Overall Satisfaction $=$ B0 + B1 (Student involvement $)+$ error

Adjusted R-squared value: 0.12

Loyalty = B0 + B1(Attitude $)+$ B2(Overall Satisfaction $)+$ B3(Descriptive Norm)

+ B4(Moral Norm) + error

Adjusted R-squared value: 0.51

$$
\begin{aligned}
& \text { Intention to Donate = B0 + B1(Prescriptive Norm })+ \text { B2(Attitude })+ \text { B3(Loyalty) } \\
& + \text { error }
\end{aligned}
$$

Adjusted R-squared value: 0.57 

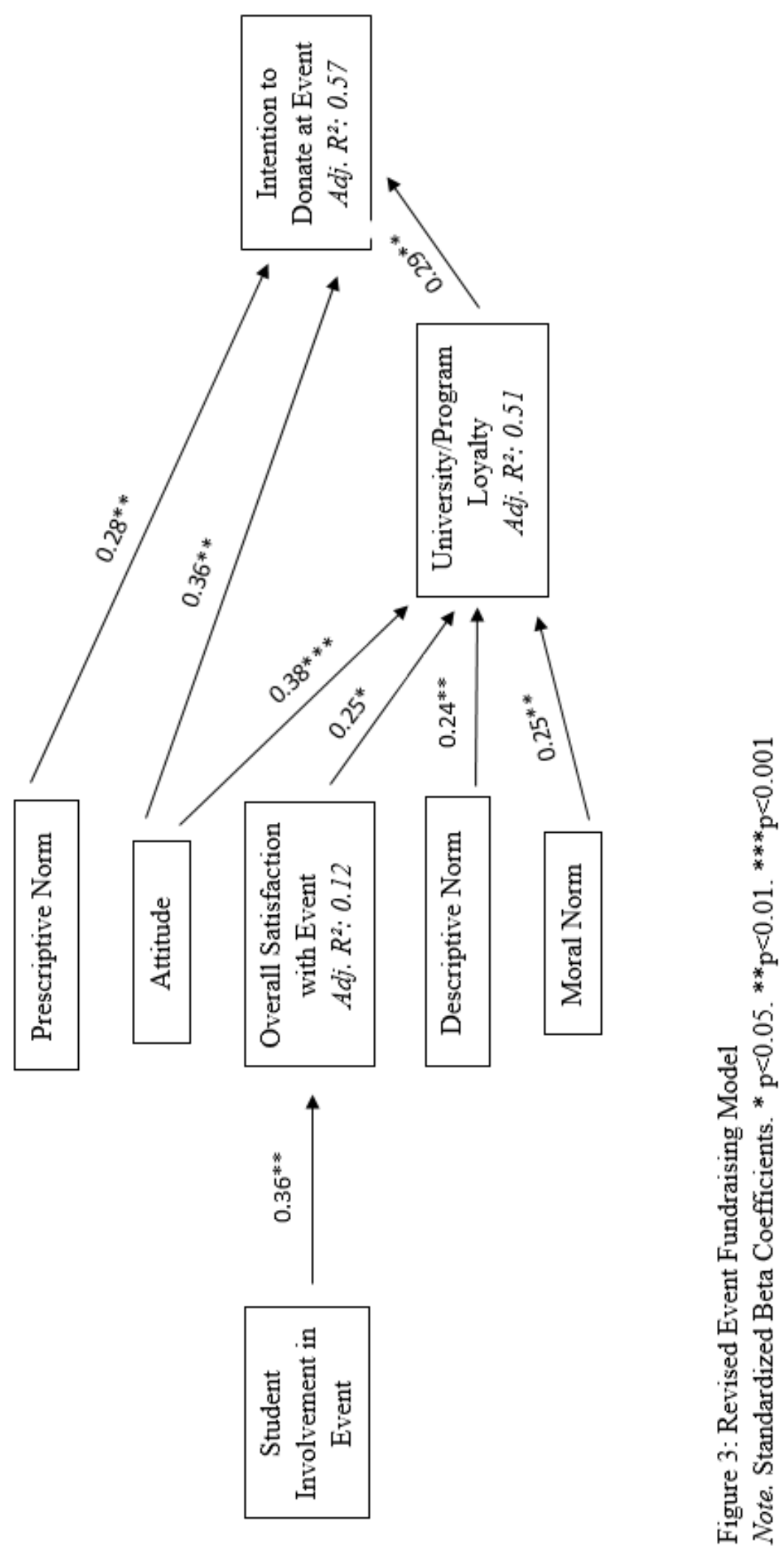


\section{Summary}

This chapter has presented results from the RPTA Auction and Dinner event survey. Through several different analyses, the initial proposed model has been altered to reflect the results of the statistical analysis in what is now referred to as the Revised Event Fundraising Model. The concluding chapter will discuss these findings, managerial and theoretical implications, and identify study limitations and opportunities for future research. 


\section{CHAPTER 5}

\section{DISCUSSION}

The purpose of this study was to apply the Revised Theory of Planned Behavior and EVENTQUAL models to explore (1) event qualities that significantly impact guests’ satisfaction with a university event that they attend, (2) significant factors influencing university loyalty as a result of an event, and (3) willingness to make a charitable donation to a university as a result of attending an event. A proposed model was developed with the goal of connecting the aforementioned variables to create a tool for university event coordinators to utilize in their fundraising event planning. This chapter will review methodology, summarize results of the study reflected in a revised model, and discuss these findings in relationship to prior research. Practical implications for these results will be discussed as well as suggestions for future research.

\section{Summary}

The results of the study provide insight into the ways in which an event is planned and executed to enhance a guest's likelihood of donating at a fundraising event. This section will address the three goals of the study as outlined in the original purpose statement, and a discussion of how the combination of this information translates into a revised event fundraising model.

The initial goal in support of the purpose of this study is to determine which event qualities significantly impact a guest's satisfaction with a university event that they attend. While Student Involvement on Quality of Event is significant in the overall revised model, it is worth noting that regressing all three event attribute variables onto the 
overall satisfaction with the event variable shows additional information. Although student involvement is highly significant in predicting overall satisfaction with the event, quality of entertainment and quality of auction items is insignificant.

The second goal in support of the purpose of this study is to examine variables that influence university loyalty. The initial proposed model only looks at overall satisfaction with the event and how well it can predict an attendee's university loyalty. While event satisfaction alone explains roughly $23 \%$ of the variance in university loyalty (Table 7), the revised event fundraising model (Figure 3) takes a much broader look at what variables influence university loyalty. Together, attitude, overall event satisfaction, descriptive norm, and moral norm explain $51 \%$ of the variance in university loyalty (Figure 3). These findings support the work of Petrick et al. (2013) that overall satisfaction is strongly related to loyalty. Further, Yoon et al. (2009) determined that event quality dimensions improve loyalty via satisfaction, directly supporting the findings of the full revised event fundraising model linking event attributes through satisfaction into loyalty. The second purpose of this study is met through the development of the Revised Event Fundraising Model in determining the significant factors influencing university loyalty.

The third goal in support of the purpose of this study is to explore an event attendee's willingness to make a charitable donation to a university as a result of attending an event. The Revised Event Fundraising Model indicates that university loyalty, attitude, and prescriptive norm are all significant predictors of intention to donate at an event. Although overall satisfaction with an event is not a significant predicting factor directly, it is significant in predicting university loyalty, which in turn influences 
intention to donate. The development of the revised model is crucial in that it connects event satisfaction with intention to donate. These findings are in contrast to earlier research on philanthropic giving. While Smith \& McSweeney (2007) and van der Linden (2011) have found attitude, perceived behavioral control, moral norm, and past behavior to influence charitable intent, the Revised Event Fundraising Model determined that attitude is the only of these variables significant in directly influencing intention to donate. Moral norm influences intention to donate through loyalty, but perceived behavioral control and past behavior are not significant predictors of either loyalty or intention to donate in this study. In contrast to the literature, prescriptive norm is a significant predictor of intention to donate in an event setting. The addition of loyalty to the two revised theory of planned behavior variables together account for $57 \%$ of the variance in predicting intention to donate. It is worth noting that although this study does not include a donation behavior variable, Ajzen (1991) found that intention is the strongest predictor of actual behavior. Consequently, those that intend to make a donation are very likely to in fact make that financial contribution. This suggests that university event attendees first must feel loyal to the university before they consider making a donation.

\section{Discussion and Practical Implications}

The development of this revised event fundraising model has several practical implications for university event planners that hope to facilitate an event that encourages philanthropic giving to the university. First, specific to university events, the utilization of students at the event is key in the guests' satisfaction with the event. This is not surprising because by including students in the event, potential donors interact with the 
people that are directly benefitting from their charitable donation. Students have the unique ability to discuss how funds brought in through the event they are attending influence their lives and help them in their education and careers. Wakelin (2013) studied motivations for students to volunteer at an event. For an event to raise the most funds, ideally having students involved as volunteers reduces expenses. Wakelin determined that the main motivations include a sense of community, experience, social purposes, a link to the cause, and fun and enjoyment. University fundraising event planners should keep this in mind when recruiting student volunteers to attending or working their event. This gives guests an opportunity to see the direct impact their contribution may have on students and exposes the student to their university’s philanthropic efforts. The strategy of including students is two-fold in that (1) guests feel their event overall satisfaction is significantly influenced by the involvement of students, and (2) these students are significantly more likely to become financial supporters once alumni as the philanthropic culture instilled is strongest while the student is still enrolled and on campus (McAlexander et al., 2006).

From an event planning perspective, the revised event fundraising model suggests that several variables influence university loyalty and intention to donate. If an event attendee is already satisfied with the event based on the involvement of students, among other factors, the event coordinator can use the revised event fundraising model as a starting point for how to help influence a guest to want to make a charitable donation at the event. This model suggests that just because a guest is satisfied with an event doesn't necessarily mean they intend to make a donation. Event coordinators can obviously shift how the event is planned in regards to various event attributes (in this case, auction items, 
entertainment, and student involvement). Encouraging guests to feel a sense of loyalty through changes in attitude, or attempting to influence descriptive or moral norms can be done through event messaging to foster a positive event experience that encourages guests to feel loyal to the university or program.

Overall, each of the variables that influence satisfaction, university loyalty, and intention to donate, should be considered on a case by case basis to determine the event type and the target audience. An event benefitting a university's student union may have a completely different message and draw different attendees than one benefitting the library or the engineering school. This revised model can be applied to any university fundraising event as long as the awareness of the event type and target audience are considered.

Study Limitations

The limitations of this study are primarily due to the limited number of subjects the researcher could email the survey to, with additional complications from the low response rate. In addition, questions of validity arise as many of the variables could be interpreted as overlapping variables by an attendee completing the survey. Also, the data are only representative of one event at one university. This event is planned and coordinated by a different team of students annually so the guest experience is not necessarily similar across the event each year. Thus, the planned event experience could not be controlled across the entire sample size. Finally, the wording on a question meant to reflect donation behavior, instead was likely interpreted by respondents to reflect past behavior. As a result, one of the initial 13 variables had to be dropped from the analysis 
as there was no question measuring donation behavior. This limitation changed the initial proposed model to not include donation behavior.

\section{Future Research}

Suggestions for future research on this topic are based on the analysis of the regression models and the limited current research examining the relationship between university events and fundraising. In the future, research on this topic could focus on a university's events over the course of a year, with strategic event branding and thorough survey follow up. Although demographics were not controlled for in this study due to the small sample size, the conclusions that could be drawn by including demographic information in the future could help event planners to understand more about their constituency and improve event marketing to that target market. Alternatively, research could examine fundraising events planned across multiple institutions. Oftentimes fundraising events simply benefit from a culture of financial philanthropy and donors utilize the event to make their charitable contribution to the university.

The purpose of this study aimed to explore event fundraising in a university setting. The initial proposed model (Figure 1) pulled together variables from an EVENTQUAL model and a Revised Theory of Planned Behavior with a series of hypotheses utilized to test the significance of these variables in the proposed model. . The conclusions of each of these models could prompt future research to solidify the findings of this study and improve upon the body of research relating university events and charitable giving. 
The first goal in support of the purpose of this study has been to examine event attributes that influence event satisfaction, tested by $\mathrm{H} 1$ and $\mathrm{H} 2$. The three variables relating to the EVENTQUAL previous research were chosen based on the type of event examined, a department's annual student-planned auction fundraising event. Although of the three event attributes examined only Student Involvement is significant in predicting Overall Event Satisfaction. However, there are a number of variables that could be explored depending on the type of event, such as the food quality and variety, or quality of programming in an event with a keynote speaker or additional programming. Event attributes to consider analyzing for an event focused on the guest's food or beverage experience, such as a winemaker dinner or champagne tasting event, could draw conclusions about both event loyalty and brand loyalty to support a charitable cause. The variety in event types utilized as fundraisers for universities opens up many potential variables to explore in future research.

The second goal in support of the purpose of this study has been to explore factors that influence university or program loyalty, tested by H3. In the initial proposed model (Figure 1), this study only examines whether Overall Event Satisfaction significantly predicts University/Program Loyalty. Simple regression analysis confirms this hypothesis (Table 7) but ultimately, a revised model has been developed and several additional variables (all revised theory of planned behavior variables and overall event satisfaction) have been tested for significance in predicting university or program loyalty (Figure 3). In studies to come, there are additional factors that could predict university or program loyalty, such as the relationship with the university. 
Additionally, wording for this particular survey did not differentiate between program loyalty and university loyalty. For this particular group, it became clear that the majority of these guests were loyal to the RPTA department, but not necessarily the university. In several cases, guests wrote in the open comment section of the survey that there is a distinction between supporting the program and supporting the university: "donating to Cal Poly is different from donating to RPTA;" "I will never make a donation to Cal Poly. I will ALWAYS make a donation to RPTA faculty/students;” "I normally do not make any donations to Cal Poly, I make them to RPTA. I am fearful that if I made a donation to Cal Poly it would not get to the RPTA department;" "The students have done a tremendous job on the RPTA Auction. I prefer to support it instead of the general Cal Poly Foundation.” Another wrote that their motivation behind attending and giving back to RPTA was the connection they had with the faculty and fellow alumni. This suggests that the reason guests feel loyal to a particular university event can vary based on the event and that event's typical audience. Future research should make a distinction between the program and university, while exploring additional reasons guests feel loyal to that program or university.

The third and final goal in support of the purpose of this study has been to examine which factors are significant in predicting a guest's intention to donate at the event, tested in H4 and H5 (with H6 removed for Donation Behavior variable exclusion). While these hypotheses are significant in helping test the proposed model (Figure 1) and ultimately create the Revised Event Fundraising Model (Figure 3), it is important to note the importance that university/program loyalty plays in predicting intention to donate. Several variables (Event Satisfaction, Descriptive Norm, and Moral Norm) are not 
significant in predicting intention to donate directly but are significant predictors of university or program loyalty.

Moving forward in university event fundraising research, this relationship between loyalty and intention to donate would be one to consider for further exploration. Perhaps additional research with a focus on loyalty (whether program or university) will help solidify the idea that event guests must feel loyal to the program or university if they ever plan to make a donation to support it. Consequently, event planners should strategize in their planning efforts to encourage loyalty as much as actual giving, shifting to a longer-term investment in the relationship with that guests, supported by this research suggesting that loyalty is a key factor in future donations. The results of this study suggest that loyalty serves as a catalyst for guests' intention to make a charitable donation, creating a new gap in university event fundraising literature to examine how best to encourage program or university loyalty through special events. 


\section{REFERENCES}

Abreu-Novais, M., \& Arcodia, C. (2013). Music festival motivators for attendance: Developing an agenda for research. International Journal of Event Management Research, 8, 34-48.

Ajzen, I. (1991). Theory of planned behavior. Organizational Behavior and Human Decision Processes, 50, 179-211.

Ajzen, I., \& Driver, B. L. (2009). Prediction of leisure participation from behavioral, normative, and control beliefs: An application of the theory of planned behavior. Leisure Sciences, $13,185-204$.

Ajzen, I., \& Madden, T. J. (1986). Prediction of goal-directed behavior: Attitudes, intentions, and perceived behavioral control. Journal of Experimental Social Psychology, 22(5), 453-474.

Ashley, A. New data capture methods can be fun and measure ROI. Conference \& Incentive Travel: 11-11, 2014.

Berridge, G. (2012). Event experience: A case study of differences between the way in which organizers plan an event experience and the way in which guests receive the experience. Journal of Park and Recreation Administration, 30(3), 7-23.

Bojanic, D. C., \& Warnick, R. B. (2012). The role of purchase decision involvement in a special event. Journal of Travel Research, 51, 357-366.

Bowdin, G., Allen, J., O’Toole, W., Harris, R., \& McDonnell, I. (2006). Events management (2nd ed.). Oxford: Butterworth-Heinemann.

Conner, M., \& Abraham, C. (2001). Conscientiousness and the theory of planned behavior: Toward a more complete model of the antecedents of intentions and behavior. Personality and Social Psychology Bulletin, 27(11), 1547-1561. 
Crompton, J. L., \& McKay, S. L. (1997). Motives of visitors attending festival events. Annals of Tourism Research, 24, 425-439.

Cunningham, G. B., \& Kwon, H. (2003). The theory of planned behaviour and intentions to attend a sport event. Sport Management Review (Sport Management Association of Australia \& New Zealand), 6, 127-145.

Darlington, H. (2009). Motivation can make you better. Supply House Times, 52(7), 45.

Getz, d., \& Cheyne, J. (2002). Special event motives and behaviour. In C. Ryan (ed.), The Tourist Experience: A New Introduction, $2^{\text {nd }}$ edn. London: Continuum Books.

Hansen, T., Jensen, J. M., \& Solgaard, H. S. (2004). Predicting online grocery buying intention: A comparison of the theory of reasoned action and the theory of planned behavior. International Journal of Information Management, 24(6), 539550.

Harris, S. (2009). Event marketing weighs investment return. Meeting News, 33(8).

IBM Corp. Released 2012. IBM SPSS Statistics for Windows, Version 21.0. Armonk, NY: IBM Corp.

Kim, M., Gibson, H., \& Ko, Y.J. (2011). Understanding donors to university performing arts programs: Who are they and why do they contribute? Managing Leisure, 16, 17-35.

Loyalty. (n.d.). Retrieved October 27, 2015, from http://www.merriamwebster.com/dictionary/loyalty

McAlexander, J. H., Koenig, H. F., \& Schouten, J. W. (2006). Building relationships of brand community in higher education: A strategic framework for university advancement. International Journal of Educational Advancement, 6(2), 107-118. 
McDearmon, J. T. (2013). Hail to thee, our alma mater: Alumni role identity and the relationship to institutional support behaviors. Research in Higher Education, 54, 283302.

Montano, D. E., Kasprzyk, D., Glanz, K., Rimer, B. K., \& Viswanath, K. (2008). Theory of reasoned action, theory of planned behavior, and the integrated behavioral model. Health Behavior: Theory, research and practice, 67-96.

Myong Jae, L. (2006). Analytical reflections on the economic impact assessment of conventions and special events. Journal of Convention \& Event Tourism, 8, 71-85.

Parker, D., Manstead, A. S. R., \& Stradling, S. G. (1995). Extending the theory of planned behavior: The role of personal norm. British Journal of Social Psychology, 34, 127-137.

Pavlou, P. A., \& Fygenson, M. (2006). Understanding and predicting electronic commerce adoption: An extension of the theory of planned behavior. MIS quarterly, 115-143.

Petrick, J. F., Bennett, G. \& Tsuji, Y. (2013). Development of a scale for measuring event attendees evaluations of a sporting event to determine loyalty. Event Management, 17, 97-110.

Smith, J. R., \& McSweeney, A. (2007). Charitable giving: The effectiveness of a revised theory of planned behaviour model in predicting donating intentions and behaviour. Journal of Community \& Applied Social Psychology, 17(5), 363-386.

van der Linden, S. (2011). Charitable intent: A moral or social construct? A revised theory of planned behavior model. Current Psychology, 30(4), 355-374.

Wakelin, D. (2013). What motivates students to volunteer at events? Event Management, 17, 63- 
75.

Yoon, Y-S., Lee, J-S., \& Lee, C-K. (2010). Measuring festival quality and value affecting visitors’ satisfaction and loyalty using a structural approach. International Journal of Hospitality Management, 29, 335-342. 


\section{APPENDICES}

Appendix A: Auction Event Attendee Survey 
* 1. Thank you for your participation in this survey.

INFORMED CONSENT TO PARTICIPATE IN A RESEARCH PROJECT, "UNIVERSITY FUNDRAISING THROUGH SPECIAL EVENTS:

AN APPLICATION OF THE THEORY OF PLANNED BEHAVIOR."

A research project on university fundraising through special events is being conducted by Megan Hobbs, a graduate student in the Department of Recreation, Parks, and Tourism Administration at Cal Poly, San Luis Obispo, under the supervision of Dr. Bill Hendricks. The purpose of the study is to apply the Revised Theory of Planned Behavior and EVENTQUAL models to explore (1) motivation for event attendance, (2) significant factors influencing university loyalty as a result of the event, and (3) willingness to make a charitable donation to a university as a result of attending an event.

You are being asked to take part in this study by completing the following questionnaire. The questions will ask about your experience at a Cal Poly auction event. Your participation will take approximately 3-5 minutes. Please be aware that you are not required to participate in this research, you may omit any items that you prefer not to answer, and you may discontinue your participation at any time without penalty. There are no risks anticipated with participating in this study. Your responses will be provided anonymously to protect your privacy. Potential benefits include enhanced ability to measure event quality and charitable giving intent.

If you have questions regarding this study or would like to be informed of the results when the study is completed, please feel free to contact Megan Hobbs at mehobbs@calpoly.edu. If you have concerns regarding the manner in which the study is conducted, you may contact Dr. Michael Black, Chair of the Cal Poly Human Subjects Committee, at (805) 756-2894, mblack@calpoly.edu, or Dr. Dean Wendt, Dean of Research, at (805) 756-1508, dwendt@calpoly.edu.

If you agree to voluntarily participate in this research project as described, please indicate your agreement by selecting the "I agree" and continuing the survey. Please print a copy of this consent form now for your reference, and thank you for your participation in this research. 
2. Auction Items (Silent and Live)

The auction items
Disagree Disagree
influenced my decision to
attend the RPTA auction
The auction items make
it worth arriving early to
the RPTA auction
The auction items add
great value to the ticket
price of the RPTA auction
The auction items are a
quality component of the
RPTA auction

The auction items add significantly to my overall experience at the RPTA auction

I'm likely to recommend attending the RPTA auction to my friends because of the auction items 
3. Involvement of Students

\begin{tabular}{|c|c|c|c|c|c|c|c|}
\hline & $\begin{array}{l}\text { Strongly } \\
\text { Disagree }\end{array}$ & Disagree & $\begin{array}{c}\text { Somewhat } \\
\text { Disagree }\end{array}$ & Neutral & $\begin{array}{c}\text { Somewhat } \\
\text { Agree }\end{array}$ & Agree & $\begin{array}{c}\text { Strongly } \\
\text { Agree }\end{array}$ \\
\hline $\begin{array}{l}\text { Student involvement } \\
\text { influenced my decision to } \\
\text { attend the RPTA auction }\end{array}$ & & & & & & & \\
\hline
\end{tabular}

Student involvement

makes it worth arriving

early to the RPTA auction

Student involvement

adds great value to the ticket price of the RPTA

auction

Student involvement is a quality component of the RPTA auction

Student involvement adds significantly to my overall experience at the RPTA auction

I'm likely to recommend attending the RPTA auction to my friends because of the involvement of students 
4. Entertainment (DJ, live music, photo booths, social media contests, etc)

The entertainment
Disagree Disagree
influenced my decision to
attend the RPTA auction
The entertainment
makes it worth arriving
early to the RPTA auction
The entertainment adds
great value to the ticket
price of the RPTA auction
The entertainment is a
quality component of the
RPTA auction

The entertainment adds significantly to my overall experience at the RPTA auction

I'm likely to recommend attending the RPTA auction to my friends because of the entertainment pieces 


\section{Satisfaction}

Strongly
Disagree Disagree
The RPTA auction is one
of the best events I have
attended
I am satisfied with my
decision to attend the
RPTA auction
I have truly enjoyed the
RPTA auction

6. Recreation, Parks, and Tourism Administration Program

I am a loyal attendee of
the RPTA auction
I like to encourage my
friends to also attend the
RPTA auction
I will attend the RPTA
auction again in the
future
Supporting the RPTA
auction is very important
to me
Supporting Cal Poly is
very important to me


7. Giving to Cal Poly in the Future

Pointless

Worthwhile

I believe that making a

charitable donation to

Cal Poly at a future RPTA

auction would be:

8. Giving to Cal Poly in the Future

No Control

Complete

Control

Overall, how much control do you think you have over donating to Cal Poly at the RPTA auction?

\section{Giving to Cal Poly in the Future}

\begin{tabular}{|c|c|c|c|c|c|c|}
\hline $\begin{array}{l}\text { Strongly } \\
\text { Disagree }\end{array}$ & Disagree & $\begin{array}{c}\text { Somewhat } \\
\text { Disagree }\end{array}$ & Neutral & $\begin{array}{c}\text { Somewhat } \\
\text { Agree }\end{array}$ & Agree & $\begin{array}{c}\text { Strongly } \\
\text { Aqree }\end{array}$ \\
\hline
\end{tabular}

The decision to donate to Cal Poly at a future RPTA auction event is entirely up to me

It is expected of me to make a charitable donation at a future RPTA auction

I believe I have a moral obligation to make a donation to Cal Poly at a future RPTA auction

I intend to make a charitable donation to Cal Poly at the RPTA auction in the future 
10. Giving to Cal Poly in the Future

Very Unlikely Unlikely
Significant others would
approve of me donating
to Cal Poly at a future
RPTA auction
How likely do you think
people close to you
(friends, family, etc)
would make a charitable
donation to Cal Poly at a
future RPTA auction?

11. Giving to Cal Poly in the Future

Not at All $\begin{gathered}\text { Very } \\ \text { Frequently }\end{gathered}$

How often have you donated money to Cal

Poly at an RPTA auction?

\section{Past Giving}

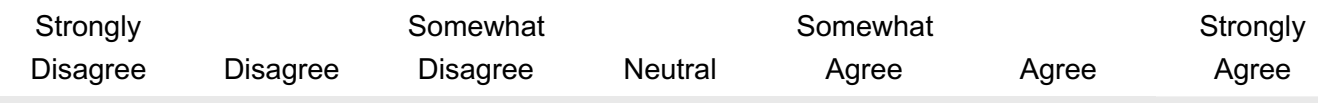

I have made a significant donation to Cal Poly at the RPTA auction 


\section{Demographics}

Age

Graduation Major and

Year (if applicable)

14. Gender

Male

Female

15. Relationship to Cal Poly (at time of event)

Cal Poly Student

$\square$ Cal Poly Alumni

Cal Poly Parent

Cal Poly Faculty/Staff

Cal Poly Supporter

\section{Annual Household Income}

$<\$ 20,000$

$\$ 20,000-\$ 34,999$

$\$ 35,000-\$ 49,999$

$\$ 50,000-\$ 74,999$

$\$ 75,000-\$ 99,999$

$\$ 100,000-\$ 150,000$

$>\$ 150,000$ 
17. Thank you for taking the time to complete this survey! Please feel free to leave any comments in the box below or leave your name and email if you are interested in receiving the results of this graduate student research. 
Appendix B: Email to RPTA Auction Event Attendees 
Email to RPTA Auction Event Attendees

SUBJECT: RPTA Auction and Dinner - Support Student Research

Friends of RPTA,

Thank you for your continued commitment to student success at Cal Poly.

As a current RPTA graduate student I am conducting research on Cal Poly’s fundraising events as part of my culminating thesis for my Master's Degree in Recreation, Parks, and Tourism Management. My research aims to improve university events to maximize university loyalty and giving that directly benefit Cal Poly's student programs and foster academic excellence.

Please consider taking 3-5 minutes to complete my online survey regarding your experience(s) at the RPTA Auction and Dinner event. I served as the Director and CEO of this event in 2014 and 2015. Your feedback would help make future improvements to this event and support RPTA graduate student research.

$<<$ SURVEY LINK $>>$

Should you have any questions regarding the research, please feel free to reach out to me directly at mehobbs@calpoly.edu.

Thank you!

Megan Hobbs 
Appendix C: Informed Consent Letter 


\section{INFORMED CONSENT TO PARTICIPATE IN A RESEARCH PROJECT, "UNIVERSITY FUNDRAISING THROUGH SPECIAL EVENTS: AN APPLICATION OF THE THEORY OF PLANNED BEHAVIOR.”}

A research project on university fundraising through special events is being conducted by Megan Hobbs, a graduate student in the Department of Recreation, Parks, and Tourism Administration at Cal Poly, San Luis Obispo, under the supervision of Dr. Bill Hendricks. The purpose of the study is to apply the Revised Theory of Planned Behavior and EVENTQUAL models to explore (1) motivation for event attendance, (2) significant factors influencing university loyalty as a result of the event, and (3) willingness to make a charitable donation to a university as a result of attending an event.

You are being asked to take part in this study by completing the following questionnaire. The questions will ask about your experience at a Cal Poly auction event. Your participation will take approximately 3-5 minutes. Please be aware that you are not required to participate in this research, you may omit any items that you prefer not to answer, and you may discontinue your participation at any time without penalty.

There are no risks anticipated with participating in this study. Your responses will be provided anonymously to protect your privacy. Potential benefits include enhanced ability to measure event quality and charitable giving intent.

If you have questions regarding this study or would like to be informed of the results when the study is completed, please feel free to contact Megan Hobbs at mehobbs@calpoly.edu. If you have concerns regarding the manner in which the study is conducted, you may contact Dr. Michael Black, Chair of the Cal Poly Human Subjects Committee, at (805) 756-2894, mblack@calpoly.edu, or Dr. Dean Wendt, Dean of Research, at (805) 756-1508, dwendt@calpoly.edu.

If you agree to voluntarily participate in this research project as described, please indicate your agreement by completing and submitting the following questionnaire. Please print a copy of this consent form now for your reference, and thank you for your participation in this research.

Yes, I volunteer.

(This “button" will open the survey.)
No, I do not volunteer.

(This "button" will exit the survey.) 